and Coatings Technology

Elsevier Editorial System(tm) for Surface

Manuscript Draft

Manuscript Number: SURFCOAT-D-19-01402R1

Title: Building up WC-Co coatings by cold spray: a finite element simulation

Article Type: Full Length Article

Keywords: Cold Spray; Hardmetal; WC-Co; Finite-element simulation; Deposition mechanism; Plastic deformation.

Corresponding Author: Dr. Giovanni Bolelli, Ph.D.

Corresponding Author's Institution: University of Modena and Reggio Emilia

First Author: Giovanni Bolelli, Ph.D.

Order of Authors: Giovanni Bolelli, Ph.D.; Sergi Dosta, Ph.D.; Luca Lusvarghi, Prof.; Tiziano Manfredini, Prof.; Josep M Guilemany, Prof.; Irene G Cano, Ph.D.

Abstract: The impact of porous $\mathrm{WC}-12 \mathrm{wt} . \circ \mathrm{Co}$ and $\mathrm{WC}-17 \mathrm{wt} . \circ \mathrm{Co}$ particles onto homologous, smooth surfaces is simulated through a coupled EulerianLagrangian, three-dimensional finite element model, in order to study the build-up mechanisms of cold sprayed WC-Co coatings.

Deformation of hardmetal particles upon impact involves compaction and spreading of a rim, whose bottom face experiences heating, close to or even above the melting point of the matrix, and develops large equivalent plastic strain. The rim therefore adheres strongly to the underlying hardmetal. SEM observations of cold sprayed WC-Co particles deposited onto a smooth hardmetal surface show metallurgic bonding of the heated matrix and mechanical fixation as WC grains from the particle indent and penetrate into the underlying material. Little deformation and heating are instead seen in the middle of the contact surface, where adhesion is limited.

Deformation of the particle requires the criterion for ductile failure of the hardmetal to be exceeded. This means the deformed rim is also extensively failed and ejects fragments as it spreads. Increasing the momentum of the particle enhances the spreading of the rim and promotes its bonding to the underlying surface, but also causes ejection of larger fragments, as well as the elastic storage of a greater amount of rebound energy, which can result in eventual rebounding of the entire particle or its poorly bonded central portion. It is therefore inferred that the deposition efficiency of cold sprayed hardmetals cannot increase linearly with impact velocity, and it is further impaired with stiff, dense particles and/or with very hard materials (e.g. WC-12Co as compared to WC-17Co). 
Dipartimento di Ingegneria "Enzo Ferrari"

Sede

Via Pietro Vivarelli, $10 \cdot 41125$ - Modena, Italia

$\mathrm{T}+390592056177 \cdot \mathrm{F}+390592056180$

www.unimore.it

www.ingmo.unimore.it

Dear Editor,

enclosed in this submission, please find the revised version of paper SURFCOAT-D-19-01402, entitled:

\section{Building up WC-Co coatings by cold spray: a finite element simulation}

By authors: Giovanni Bolelli, Sergi Dosta, Luca Lusvarghi, Tiziano Manfredini, J.M. Guilemany, I.G. Cano

which we would like to submit for publication in Surface and Coatings Technology.

All of the useful indications from the reviewers, as well as the editorial remarks, were followed in the preparation of the revised manuscript.

Detailed responses can be found in the "Response-to-reviewers" file; moreover, all changes to the text are highlighted in yellow colour.

My co-authors and I hope that this revised paper can be found suitable for publication in Surface and Coatings Technology.

I send you, also on behalf of all co-authors,

Best regards,

Giovanni Bolelli

Department of Engineering "Enzo Ferrari"

University of Modena and Reggio Emilia

Via Pietro Vivarelli 10/1

I-41125 Modena (MO), Italy

Tel.: 00390592056233

Fax: 00390592056243

e-mail: giovanni.bolelli@unimore.it 


\section{Response to Editor and reviewers}

\section{$\underline{\text { Editor's comment }}$}

Please also remove the black bars with the superfluous information at the bottom of the SEM micrographs in Figures 1 and 2 and add clearly readable scale bars (as in the other SEM micrographs in Figures 4, 5 and 9-11).

The mentioned figures were modified as requested. In Figure 2, in particular, the former SEM micrograph was replaced with two original ones, showing both types of feedstock powders and not previously published.

\section{Reviewer\#1}

Presented manuscript is very interesting, well written and organised. However, some questions suggestions came out while reading it. Authors can find it in the attached file.

The authors would like to thank the reviewer for the useful comments.

All changes, including figure modifications and clarifications to the text, have been performed as requested.

Specifically:

- The final statement of the Introduction has been revised as follows:

"The present paper therefore aims to provide an understanding of the build-up of WC-Co coatings by cold spraying. The impact of WC-12wt.\% Co and WC-17wt.\%Co particles onto surfaces consisting of identical materials was simulated by finite element modelling and morphologies were compared to those obtained through actual cold-spray experiments."

- Figure 1 was modified, trying to make the stress-strain curves more readable.

The issue lies primarily in the limited quality of the original source, i.e. the WC-Co stress-strain diagrams contained in the pdf distribution of the cited NACA Technical Note (a scan of a typescript document).

We tried to import the diagrams with higher resolution and produce a new image using a different software (Inkscape, an open source drawing and image processing package) that works with vector, rather than pixel, graphics. This should avoid pixilation.

The pdf manuscript version generated for review probably downgrades the image to a lower resolution in any case, but, by downloading the original file, it should now be possible to zoom in while preserving good quality. We hope this is now acceptable. In any case, please note that the purpose of providing the stress-strain curves is merely "illustrative", i.e. to give the reader a qualitative idea of what the curves look like. A reader who would like to extract data is redirected to the original publication, cited in the figure and the caption.

- The powders are obtained by agglomeration and sintering, and provided by Fujimi Inc. (Kiyosu, Japan). Agglomerated particle size distribution for both powders is $+32-10 \mu \mathrm{m}$, with a mean particle size of $20 \mu \mathrm{m}$, with a mean WC particle size below $1 \mu \mathrm{m}$. This information is now provided in Section 2.4.

- The substrate material was the same as the particle's. This is what it was meant by the term "homologous" in the original submission. In order to try making the concept clearer, the statement was revised as "onto smooth surfaces consisting of the same materials" (Section 2.4).

- Some lines were added to Section 2.4 to explain why HVOF spraying process was chosen to manufacture the layers onto which the cold spray particles were collected. 
Basically, since cold-spraying of hardmetals is not optimized yet (it is the goal of the present paper to understand how to optimize them), HVOF-spraying gives more confidence to deposit the thick layers that are needed as surface for the collection of cold-sprayed particles.

- Figure 4, 5, 7, 8 were revised in order to enlarge the color bar labels.

- Figure 13 was re-plotted with reversed color scale layout (from highest to lowest), as requested.

- Deposition efficiency of CGS for WC-17Co is $21 \%$ and for WC-12Co is $14 \%$. This data is now added at the end of Section 3.4.

\section{Reviewer \#2}

Very high level paper, full of information, results from both modeling and experiments, and original contributions to the understanding of the Cold Spray deposition of CerMet coatings. The only, minor, weak point is that the deposition parameters were not reported in the document, but the authors refer to two previous articles (references [19] and [23]). However, in both articles the parameters were not reported, but there were further references to previous articles.

The authors are thankful to the reviewer for the appreciation expressed.

The cold spray parameters' table was added to the paper (Section 2.4, Table IV) as follows:

\begin{tabular}{|l|l|l|l|l|}
\hline Powder & Pressure (bar) & Temperature $\left({ }^{\circ} \mathrm{C}\right)$ & Distance $(\mathrm{mm})$ & $\begin{array}{l}\text { Feeding rate } \\
(\mathrm{g} / \mathrm{min})\end{array}$ \\
\hline WC-12Co & 30 & 800 & 10 & 45 \\
\hline WC-17Co & 25 & 800 & 10 & 45 \\
\hline
\end{tabular}




\section{Highlights}

Cold sprayed WC-Co particles flatten onto a relatively undeformed hardmetal surface

Ductile failure of the hardmetal is an integral part of the particle flattening process

The particle rim is deformed and heated; it bonds metallurgically to the underlying surface

The rim ejects material fragments during its spreading process

Deposition efficiency does not increase linearly with particle impact velocity 


\title{
Building up WC-Co coatings by cold spray: a finite element simulation
}

Giovanni Bolelli $^{1^{*}}$, Sergi Dosta ${ }^{2 *}$, Luca Lusvarghi ${ }^{1,3}$, Tiziano Manfredini ${ }^{1,3}$, J.M. Guilemany ${ }^{2}$, I.G. $\mathrm{Cano}^{2}$

${ }^{1}$ Dipartimento di Ingegneria “Enzo Ferrari”, University of Modena and Reggio Emilia, Via Pietro Vivarelli 10/1, I-41125 Modena (MO), Italy

${ }^{2}$ Thermal Spray Centre (CPT), Dept. Ciència de Materials i Química Física, Universitat de Barcelona, C/ Martí i Franqués 1, 08028. Barcelona, Spain.

${ }^{3}$ Consorzio Interuniversitario Nazionale per la Scienza e Tecnologia dei Materiali (INSTM), Local Unit Università di Modena e Reggio Emilia, Via Pietro Vivarelli 10/1, 41125 Modena (MO), Italy

* Corresponding authors

G. Bolelli: Tel. +39 0592056233; Fax +39 0592056243; e-mail giovanni.bolelli@ unimore.it

S. Dosta: e-mail sdosta@ cptub.eu

\begin{abstract}
The impact of porous WC-12wt.\%Co and WC-17wt.\%Co particles onto homologous, smooth surfaces is simulated through a coupled Eulerian-Lagrangian, three-dimensional finite element model, in order to study the build-up mechanisms of cold sprayed WC-Co coatings.
\end{abstract}

Deformation of hardmetal particles upon impact involves compaction and spreading of a rim, whose bottom face experiences heating, close to or even above the melting point of the matrix, and develops large equivalent plastic strain. The rim therefore adheres strongly to the underlying hardmetal. SEM observations of cold sprayed WC-Co particles deposited onto a smooth hardmetal surface show metallurgic bonding of the heated matrix and mechanical fixation as WC grains from the particle indent and penetrate into the underlying material. Little deformation and heating are instead seen in the middle of the contact surface, where adhesion is limited.

Deformation of the particle requires the criterion for ductile failure of the hardmetal to be exceeded. This means the deformed rim is also extensively failed and ejects fragments as it spreads. Increasing 
the momentum of the particle enhances the spreading of the rim and promotes its bonding to the underlying surface, but also causes ejection of larger fragments, as well as the elastic storage of a greater amount of rebound energy, which can result in eventual rebounding of the entire particle or its poorly bonded central portion. It is therefore inferred that the deposition efficiency of cold sprayed hardmetals cannot increase linearly with impact velocity, and it is further impaired with stiff, dense particles and/or with very hard materials (e.g. WC-12Co as compared to WC-17Co).

Key-words

Cold Spray; Hardmetals; WC-Co; Finite-element simulation; Deposition mechanism; Plastic deformation. 


\section{Introduction}

Cold gas dynamic spraying or, briefly, cold spraying (CS) is one of the most recent additions to the family of thermal spray processes, and stands out for being a purely solid-state deposition process $[1,2]$.

Namely, in CS, a feedstock powder is dragged by a supersonic gas flow, generated by expanding a high-pressure gas (typically nitrogen, helium or air) through a converging-diverging (De Lavaltype) nozzle. Solid particles thus acquire very high kinetic energy, which is subsequently converted into inelastic strain energy upon impact onto the target surface [1,3-5]. In order to increase the velocity of the expanded jet, the stagnation temperature of the high-pressure gas at the torch inlet can be increased by electrical resistance heating, up to $\approx 1100{ }^{\circ} \mathrm{C}$ in the most recent $\mathrm{CS}$ equipment available on the market. Some heat is also transferred to the powder particles, which, however, do not attain the same temperature as the gas [3], both because the latter is significantly cooled as soon as it expands through the nozzle $[1,3]$, and because the residence time of the particles in the gas jet is extremely short (few milliseconds [6,7]). Particles can therefore achieve better ductility by being heated by the gas, but, even in the case of materials with low melting point (e.g. Al, Zn), no liquid phase is formed: deformation and adhesion of the particles occurs by plastic deformation in the solid state [3-5].

Extensive numerical and experimental studies have led to the formulation of comprehensive, though partly contradictory, theories for the deposition of ductile metals $[3,8]$. The most established theory assumes that cold spray deposition of metals relies on adiabatic shear instabilities at the interface between the impacting particle and the underlying surface [5]. In the contact region, the kinetic energy of the particle is dissipated by plastic deformation over times of few tens of nanoseconds, generating heat at a faster rate than it can be removed by conduction. Local temperature therefore increases by a thermal boost-up phenomenon $[9,10]$, until it reaches a point when the rate of recovery and recrystallization of the deformed metal balances the generation rate of dislocations 
[11-13]. Further deformation remains localized in this thermally-softened area, disrupting the tiny native oxide film that covers the surface and allowing for intimate metal-to-metal bonding; moreover, the roughened interface that results from extrusion of the substrate material in between the deposited particles produces additional mechanical interlocking [4]. A more recent theory contends that the tight interface bonding follows from a shockwave effect [14]: the topic is still the subject of an active ongoing debate $[15,16]$. According to this theory, the impact produces a highpressure shockwave advancing through the particle and the underlying surface. When the shockwave detaches from the edge of the particle/substrate contact region, the reflected wave produces correspondingly high hydrostatic tension at the same contact edge. This hydrostatic tension, exceeding the material strength, produces metal jetting which results in interface bonding. Both theories have led to the definition of a quantitative parameter to predict the deposition efficiency. Specifically, the condition to achieve deposition is $\eta=V / V_{C r i t}>1$, where $V$ is the particle impact velocity and $V_{\text {Crit }}$ is a critical velocity threshold depending on material properties and temperature. The fraction of bonded particles increases with $\eta$, until $V$ reaches the erosion threshold [17].

Cold spray deposition of hard materials, such as ceramics or hardmetals, is more difficult, yet possible [11]. WC-Co hardmetals could particularly benefit from the use of CS, since it provides dense coatings [18-20] without the unavoidable decarburization that necessarily comes with melting of the metal matrix in high-temperature processes, such as High Velocity Oxygen-Fuel (HVOF) spraying [21]. The mentioned studies, as well as similar research on $\mathrm{Cr}_{3} \mathrm{C}_{2}-\mathrm{NiCr}$ compositions [22], accordingly show very promising results in terms of wear and corrosion resistance. Deposition mechanisms, however, are not fully understood. Due to the composite nature of hardmetal particles, containing a ceramic phase embedded in a metal matrix, direct application of the above-mentioned theories developed for pure metals is not possible.

The authors have already investigated the phenomena involved in the deposition of the first layer of WC-based hardmetal particles onto a ductile metallic substrate [23]. Barely deformed hardmetal 
particles were seen to penetrate deep into the substrate, which undergoes very localized heating and plastic deformation, developing a composite interface layer. Likewise, Fernandez and Jodoin studied the deposition of chromium carbide hardmetal particles onto metal substrates, again showing little particle deformation upon impact, and highlighting the critical relevance of particles' morphology and microstructure (including their porosity, carbide size and distribution, volume fraction of metal matrix) for proper deposition [24].

The growth of the coating beyond the interfacial layer, however, relies on the deposition of hardmetal particles onto pre-deposited hardmetal. This phenomenon has not been described yet. The present paper therefore aims to provide an understanding of the build-up of WC-Co coatings by cold spraying. The impact of WC-12wt.\%Co and WC-17wt.\%Co particles onto surfaces consisting of identical materials was simulated by finite element modelling and morphologies were compared to those obtained through actual cold-spray experiments.

\section{Finite element modelling}

\subsection{Description of the modeling approach}

In order to simulate the impact of a hardmetal particle, two distinct approaches can be adopted. Fernandez and Jodoin [24] used 2D plane-strain models built onto the actual cross-sections of $\mathrm{Cr}_{3} \mathrm{C}_{2}-\mathrm{NiCr}$ powder particles, imaged through scanning electron microscopy (SEM). This approach allows accounting for the real microstructure, with an accurate depiction of the shape, size and distribution (at least in a bi-dimensional representation) of carbide particles. Notable disadvantages, however, include a lack of generality (in a given feedstock powder, microstructural details of distinct particles can vary to some extent) and failure to account for the three-dimensional nature of the real system. Using a plane-strain model, for example, means that the particle behaves more like a cylinder of infinite axial length than as a rounded, approximately spherical body. Other papers employed full 3D models, where the hardmetal has to be modeled as a homogeneous material, since 
re-constructing the actual 3D microstructure of a WC-Co particle with sub-micrometric carbide grains would result in an excessively large number of very small elements. This approach was chosen by the present authors in their previous study of cold-sprayed hardmetal particles impacting onto metal [23], as well as by Kamnis et al. to study the HVOF deposition of WC-Co hardmetals onto steel substrate [25-27], and was therefore retained in the present work.

In a cold-spray impact model of a particle with homogeneous material assumption, it is particularly important to use realistic mechanical properties. In [28], it was suggested that the plasticity parameters for the constitutive model of a metallic powder particle be measured by a compression test. This, however, is impractical for agglomerated and sintered WC-Co particles: their irregular shape would render all data analysis procedures described in [28] approximate at best; their brittleness and inner porosity would also result in sudden crushing, rather than in continuous plastic deformation.

It was therefore decided to obtain (static) elastic-plastic parameters for the dense hardmetal through a microstructure-based finite element model, and to account explicitly for porosity in the geometrical model of the particle, similar to the approach employed to model the HVOF deposition of WC-Co in [26], albeit in a simplified manner. Porosity is indeed known to be critical to the deformation of hardmetal particles, in both cold- [24] and HVOF-spraying [26]. Pores were introduced as a three-dimensional array of $3 \mu \mathrm{m}$-diameter, spherical cavities with $8 \mu \mathrm{m}$ centercenter spacing in all directions (see Section 2.3).

Specifically, the static elastic-plastic parameters of the dense hardmetal were obtained by simulating a uniaxial compression test on the cross-section of a complete cold-sprayed coating (Section 2.2), assuming, at least as a first approximation, that the distribution of matrix and carbide phases in the hardmetal represent a "densified version" of the same distribution in the porous, agglomerated and sintered particles.

Strain-rate and temperature dependence, as well as failure parameters, were instead drawn from the literature, as explained later in Section 2.3. 


\subsection{Microstructure-based modeling of hardmetal properties}

Finite element meshes were built onto 4000× SEM micrographs acquired in backscattered electrons imaging mode onto the polished cross-sections of WC-12wt.\%Co and WC-17wt.\%Co CS coatings (experimental details in Section 2.4), with $1536 \times 1103$ pixel size and imaging a $41.5 \times 29.8 \mu \mathrm{m}$ field of view (Figure 1). Ten images were employed for each material. Micrographs were pre-processed using open-source software (Gimp 2.8 and ImageJ) in order to turn them into two-color binary images, onto which finite element meshes were built using the OOF2 software [29]. Meshes were exported in ABAQUS-compatible format.

Images were meshed using approximately 150000 - 200000 6-node triangular elements, with an element size of $\approx 0.16 \mu \mathrm{m}$ in homogeneous regions and down to $\approx 0.05 \mu \mathrm{m}$ close to two-phase boundaries.

As seen in Figure 1, WC and Co phases are not evenly distributed: WC-rich regions, consisting of very fine (almost nanometric) hard-phase particles bound by a smaller amount of metal matrix, are interspersed with areas of pure Co ("Co lakes"). Quantitative image analysis carried out on the same SEM micrographs using the ImageJ (NIH, Bethesda, MA, USA) software shows that, in both WC$12 \%$ Co and $\mathrm{WC}-17 \%$ Co compositions, the WC-rich regions contain $\approx 16.5$ vol.\% (i.e. $\approx 10 \mathrm{wt} \%$ ) cobalt, the remainder being localized in the "Co lakes", which are more abundant $(\approx 12$ vol.\%) in WC-17\%Co than in WC-12\%Co ( $\approx 4$ vol. $\%)$.

Since it is almost impossible to tell precisely each individual WC grain in the hard phase-rich areas, the latter were modeled as a homogeneous material having the properties of $\mathrm{WC}-10 \mathrm{wt} . \% \mathrm{Co}$. Due to the large fraction of the WC ceramic phase, the yield behavior of WC-10wt.\%Co cannot be described by the isotropic Von Mises criterion. Literature data indeed shows considerable differences between compressive and tensile yield strengths [30]. A linear Drucker-Prager yield criterion was therefore employed, in the (simplified) assumption of associated flow (Eq. 1) [31]. 


$$
\sigma_{e q}-p \cdot \tan (\beta)=d
$$

Where: $\sigma_{e q}=$ Von Mises equivalent stress; $p=$ hydrostatic pressure component; $\beta=$ friction angle; $d$ $=$ material cohesion.

This constitutive relation describes materials with higher yield strength under hydrostatic compression, such as it usually happens for ceramics.

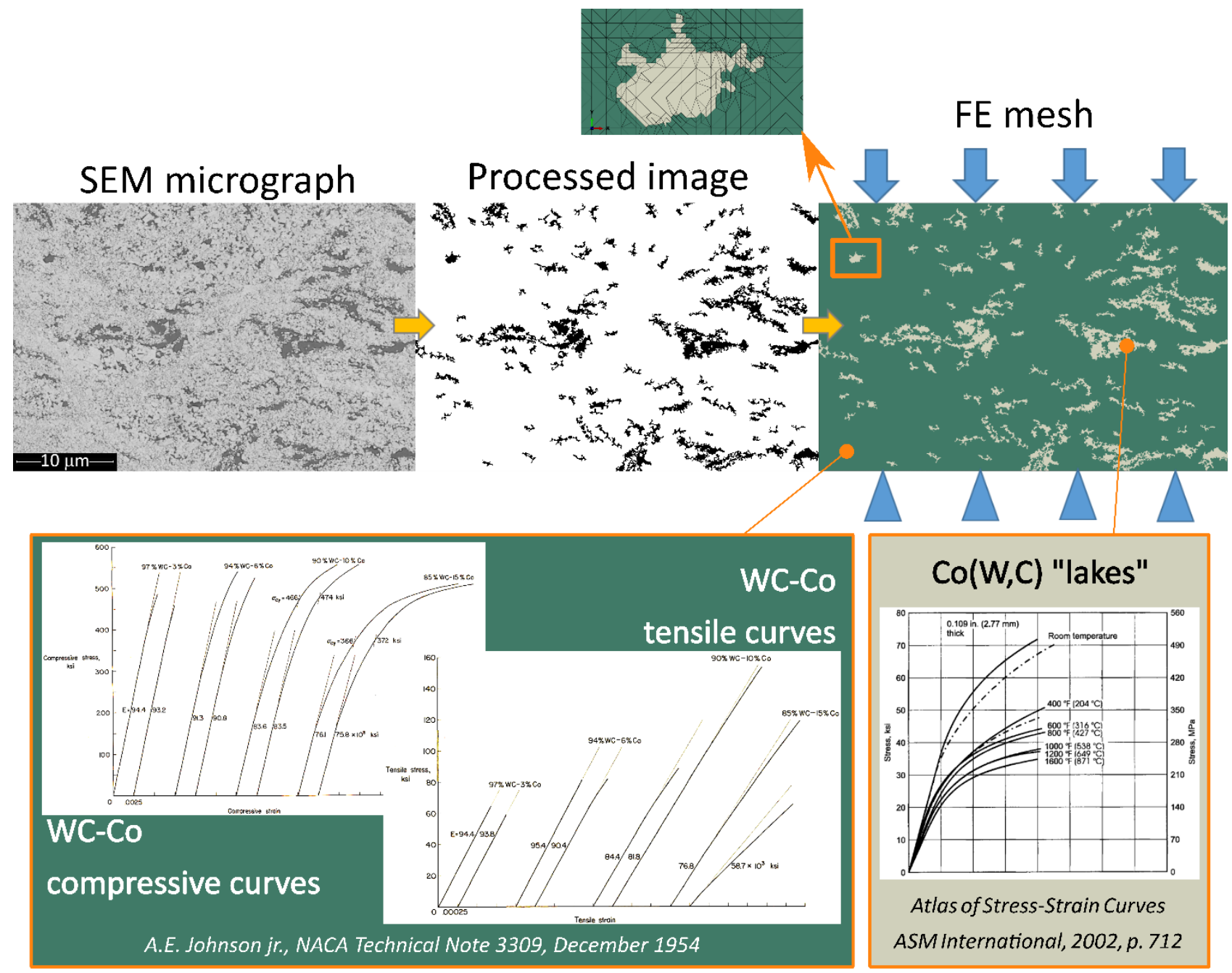

Figure 1. Procedure for microstructure-based finite element modeling of the properties of the dense hardmetal: a cross-sectional SEM micrograph of a cold-sprayed coating is made into a binary image and meshed, assigning the respective material properties to each phase with literature data (WC10\% Co: [30]; $\mathrm{Co}(\mathrm{W}, \mathrm{C})$ lakes: [32]).

Since values of $\beta$ and $d$ are not available in the open literature, they were computed according to Eqs. 2.1 and 2.2, which are obtained by re-writing Eq. 1 itself for uniaxial tensile and compressive stress conditions, and solving for the mentioned parameters. The uniaxial tensile $\left(\sigma_{t}\right)$ and 
compressive $\left(\sigma_{c}\right)$ yield strength values were obtained from the stress-strain curves published in [30]:

$$
\begin{gathered}
\tan (\beta)=3 \frac{\sigma_{c}-\sigma_{t}}{\sigma_{c}+\sigma_{t}} \\
d=\left[1-\frac{1}{3} \tan (\beta)\right] \sigma_{c}
\end{gathered}
$$

Strain-hardening was further considered by using data beyond the yield point in the compressive stress-strain curve of WC-10wt.\%Co provided in [30].

The "Co lakes", on the other hand, were modeled using the isotropic Von Mises yield criterion with data from the room-temperature stress-strain curve of Stellite-25 published in [32]. This was chosen both because of the unavailability of literature data for pure cobalt, and because the Co matrix in hardmetal powders always contains small amounts of dissolved $\mathrm{W}$ and $\mathrm{C}$ from the sintering process, which make it harder than pure cobalt. Data was entered in tabular form into the finite element model.

Simulated compression tests were run using the ABAQUS 2016 software, imposing a linearly increasing compressive stress on the top surface of the model whilst the bottom surface was fixed along the y-direction (Figure 1). Symmetry along the x-direction was imposed on the right boundary; the left boundary was free to move but constrained to remain straight, in order to avoid unphysical deformations. By plotting modeled strains as a function of the applied compressive stress, a stress-strain curve was obtained. The linear portion of the curve was fitted to obtain the elastic modulus, whilst the plastic part was fitted with a power-law relation (eq. 3):

$$
\sigma=A+B \cdot \varepsilon_{p}^{n}
$$

where $\sigma$ is the applied stress, $\varepsilon_{\mathrm{p}}$ the plastic strain, $A, B$ and $n$ are fitting parameters. These fitted parameters were employed as input to the constitutive model of the material in subsequent finite element simulations of single-particle impacts (Section 2.3). 


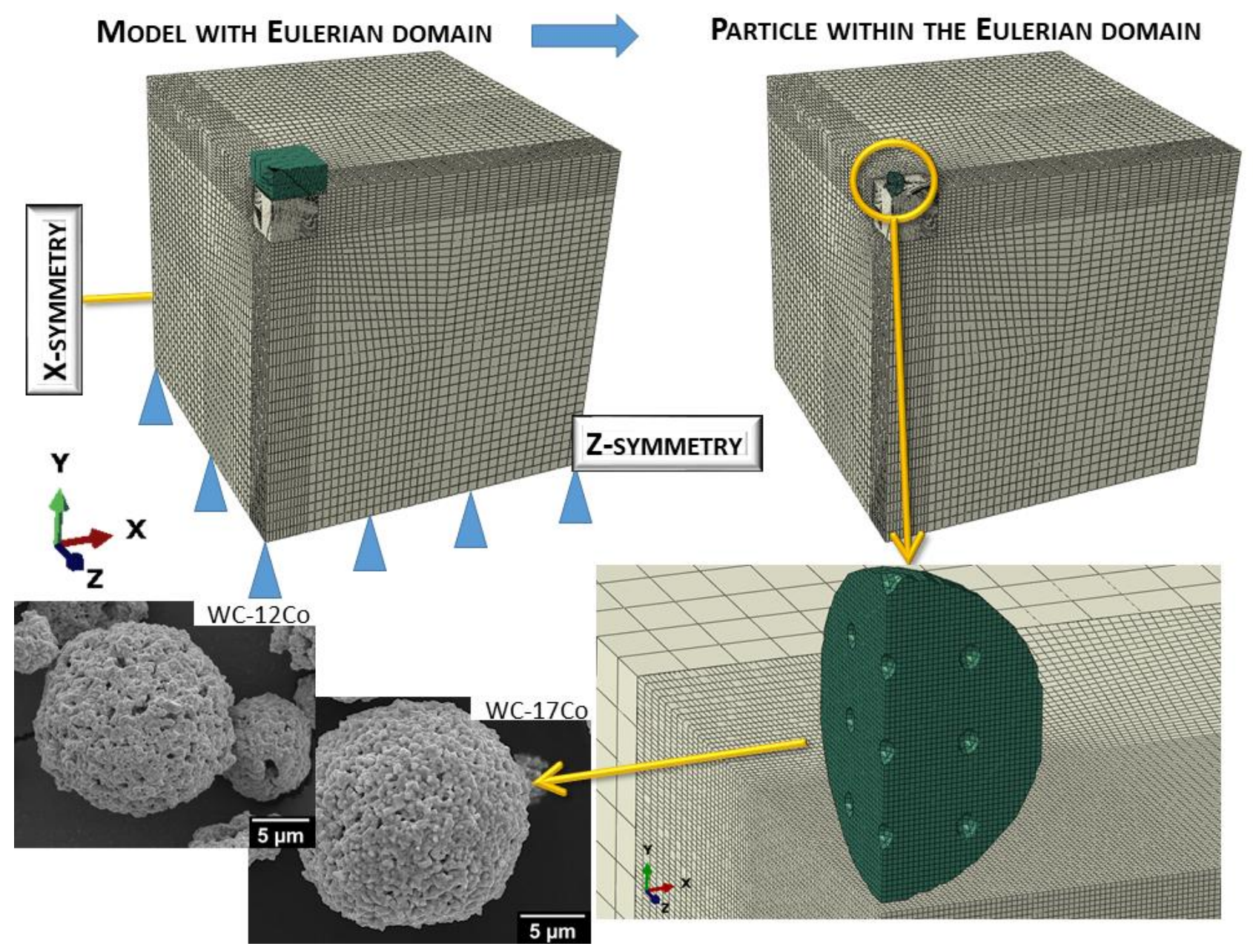

Figure 2. Mixed Lagrangian-Eulerian model of single-particle impact, including a simplified geometrical representation of actual porosity within the particle - compare to the actual SEM micrographs.

Simulations were run using a $30 \mu \mathrm{m}$-diameter, spherical hardmetal particle impacting onto a substrate made of the same hardmetal. Pores were introduced in the particle as a regular array of 3 $\mu \mathrm{m}$-diameter voids at a spacing of $8 \mu \mathrm{m}$ (center-center), as anticipated in Section 2.1. Exploiting the symmetry of the system, only one quarter of the particle and the substrate were modeled (Figure 2). Additional simulations were run with a fully dense particle, as a term of comparison.

According to various authors [14,33-37], simulating particle impacts in cold spraying by a coupled Eulerian-Lagrangian approach, where the substrate is modeled as a Lagrangian object whilst the particle is tracked within a Eulerian domain with fixed elements, could be preferable over a pure 
Lagrangian model, since, in the latter case, extreme distortion of elements near the contact surface can affect the outcomes. In the present work, based on preliminary comparative analyses performed using both Lagrangian and coupled Eulerian-Lagrangian models, the latter was chosen as it yielded more realistic results. The particle was therefore tracked within a Eulerian domain meshed with $\approx 0.5 \mu \mathrm{m}$-size hexahedral elements (Figure 2). Element size was chosen to be less than $1 / 50$ th of the particle diameter, which is the threshold below which mesh dependence is minimized in such impact simulations [14]. The substrate was meshed with 8-node, Lagrangian hexahedral elements. Finer mesh size $(\approx 0.5 \mu \mathrm{m})$ was employed in the impact area, whereas a coarser mesh was adopted away from the impact location. The overall size of the substrate was much larger than that of the particle, in order to avoid stress reflection artefacts at the model boundaries.

Simulations were performed with particle velocities of 400, 500, 600, $700 \mathrm{~m} / \mathrm{s}$ and particle temperatures of 700,850 and $1000 \mathrm{~K}$, which cover a realistic range of potentially achievable values around the actual velocities and temperatures listed in [23]. The substrate was always assumed to be at $373 \mathrm{~K}$.

Von Mises isotropic plasticity was assumed for the hardmetal phase: this is indeed the standard approach employed to model not only the HVOF deposition of hardmetals [25-27], but also the ballistic impact of WC-Co projectiles [38-41]. Specifically, the dependence of stress on plastic strain, strain rate and temperature was described analytically by the Johnson-Cook model (eq. 4) [42]:

$$
\sigma_{e q}=\left(A+B \varepsilon_{p}^{n}\right)\left(1+C \frac{\dot{\varepsilon}}{\dot{\varepsilon}_{0}}\right)\left(1-T^{*}\right)^{m}
$$

Where: $\sigma_{e q}=$ Von Mises equivalent stress; $\varepsilon_{p}=$ equivalent plastic strain $\dot{\varepsilon}=$ strain rate $A=$ yield stress; $B=$ strain-hardening modulus; $n=$ strain-hardening exponent; $C=$ strain-rate hardening coefficient; $\dot{\varepsilon}_{0}=$ reference strain rate; $T^{*}=\left(T-T_{0}\right) /\left(T_{m}-T_{0}\right)=$ nondimensional temperature; $T_{0}$ $=$ reference temperature $; T_{m}=$ melting temperature $m=$ temperature-dependence exponent. 
The static parameters $A, B, n$ were obtained by fitting the simulated compressive stress-strain curves as described in Section 2.2, in order to achieve a more realistic representation of the actual material behavior. All other parameters were obtained from the literature [26].

Failure of the hardmetal was also included in the simulations: failure was assumed to begin once the accumulated plastic strain exceeds a threshold value $\varepsilon_{D}^{p l}$, defined according to the Johnson-Cook failure model (eq. 5) [42]:

$$
\bar{\varepsilon}_{D}^{p l}=\left[\left(d_{1}+d_{2} \exp \left(d_{3} \frac{p}{\sigma_{e q}}\right)\right]\left(1+d_{4} \ln \left(\frac{\dot{\varepsilon}}{\dot{\varepsilon}_{0}}\right)\right)\left(1-d_{5} T^{*}\right)\right.
$$

Where $d_{l}, \ldots, d_{5}$ are experimental parameters and the other symbols have the meanings defined previously. No information is available in the literature concerning the strain-rate and temperature dependence of the failure strain (parameters $d_{4}$ and $d_{5}$ ); hence, Holmquist et al. [41] proposed using a simplified form (eq. 6):

$$
\varepsilon_{D}^{p l} \approx d_{2} \exp \left(d_{3} \frac{p}{\sigma_{e q}}\right)
$$

According to [41], the optimal value for the stress triaxiality term is $d_{3}=3$, which was therefore adopted in the present case as well. The proposed value for $d_{2}$ is, instead, very low, and, according to [38], it leads to underestimated failure strains which result in unrealistically premature fragmentation of WC-Co. The value for $d_{2}$ was therefore adjusted in order for the failure strain $\varepsilon_{D, c o m p r}^{p l}$ under uniaxial compression $\left(p / \sigma_{e q}=-1 / 3\right)$ to match the maximum strain value shown in the experimental compressive stress-strain curve of WC-15\%Co [30] (taken as an intermediate between the present WC-12\%Co and WC-17\%Co formulations): $\varepsilon_{D, \text { compr }}^{p l} \approx d_{2} / e=0.014 \Rightarrow$ $d_{2}=0.037$ (which is approx. 20 times as large as the value originally proposed by Holmquist et al. [41]).

Once failure begins, the stiffness of the failed material is linearly degraded until the deformation energy equals the fracture energy [43].

All parameters employed in the simulation are listed in Table I - Table III. 
Table I. Elastic-plastic properties of WC-17\%Co employed in the present simulations.

\begin{tabular}{r|l|l|l}
\multicolumn{2}{|l|}{ Parameter } & Source \\
\hline $\begin{array}{r}\text { Johnson-Cook } \\
\text { plasticity } \\
\text { parameters }\end{array}$ & $\mathrm{A}[\mathrm{GPa}]$ & 0.181 & $\begin{array}{l}\text { Power-law fitting of stress-plastic } \\
\text { strain curves from microstructure- } \\
\text { based simulations }\end{array}$ \\
\cline { 2 - 3 } & $\mathrm{B}[\mathrm{GPa}]$ & 24.262 & \\
\cline { 2 - 3 } & $\mathrm{m}$ & 0.386 & \\
\cline { 2 - 3 } & $\mathrm{C}$ & 1.34 & \\
\cline { 2 - 3 } & $\mathrm{T}_{\mathrm{m}}, \mathrm{T}_{\mathrm{r}}[\mathrm{K}]$ & 1580,298 & \\
\cline { 2 - 3 } & $\dot{\boldsymbol{\varepsilon}}_{\mathbf{0}}\left[\mathrm{s}^{-1}\right]$ & $1[33]$ & \\
\hline$E[G P a]$ & $463(@ 293 \mathrm{~K}) \rightarrow 100(@ 1273 \mathrm{~K})$ & \\
\hline$v$ & 0.23 & &
\end{tabular}

Table II. Elastic-plastic properties of WC-12\%Co employed in the present simulations.

\begin{tabular}{r|l|l|l}
\multicolumn{3}{|c|}{ Parameter } & Source \\
\hline $\begin{array}{r}\text { Johnson-Cook } \\
\text { plasticity } \\
\text { parameters }\end{array}$ & $\mathrm{A}[\mathrm{GPa}]$ & 0.024 & $\begin{array}{l}\text { Power-law fitting of stress-plastic } \\
\text { strain curves from microstructure- } \\
\text { based simulations }\end{array}$ \\
\cline { 2 - 3 } & $\mathrm{B}[\mathrm{GPa}]$ & 29.44 & \\
\cline { 2 - 3 } & $\mathrm{m}$ & 0.334 & \multirow{2}{*}[44]{} \\
\cline { 2 - 3 } & $\mathrm{C}$ & 1.34 & \\
\cline { 2 - 3 } & $\mathrm{T}_{\mathrm{m}}, \mathrm{T}_{\mathrm{r}}[\mathrm{K}]$ & 1580,298 & \\
\hline & $\dot{\varepsilon}_{\mathbf{0}}\left[\mathrm{s}^{-1}\right]$ & $1[33]$ & \\
\hline$E[G P a]$ & $571(@ 293 \mathrm{~K}) \rightarrow 233(@ 1273 \mathrm{~K})$ & \\
\hline$v$ & 0.23 & &
\end{tabular}

Table III. Common properties of WC-12\%Co and WC-17\%Co employed in the present simulations.

\begin{tabular}{r|l|l|l}
\multicolumn{2}{|l|}{ Parameter } & Source \\
\hline $\begin{array}{r}\text { Failure } \\
\text { parameters }\end{array}$ & $\mathrm{d}_{2}$ & 0.037 & $\begin{array}{l}\text { Calculated based on data in [30] (Section } \\
2.2)\end{array}$ \\
\cline { 2 - 3 } & $\mathrm{d}_{3}$ & 3 & {$[41]$} \\
\hline$\rho\left(\mathrm{kg} / \mathrm{m}^{3}\right)$ & 13645 & {$[45]$} \\
\hline$\alpha\left[\mathrm{K}^{-1}\right]$ & $6.61(@ 323 \mathrm{~K}) \rightarrow 7.20(@ 923 \mathrm{~K})$ & \\
\hline$c_{p}\left[\mathrm{~J}(\mathrm{~kg} \cdot \mathrm{K})^{-1}\right]$ & $239(@ 323 \mathrm{~K}) \rightarrow 305(@ 923 \mathrm{~K})$ & \\
\hline$\kappa\left[\mathrm{W}(\mathrm{m} \cdot \mathrm{K})^{-1}\right]$ & $29.2(@ 323 \mathrm{~K}) \rightarrow 35.4(@ 923 \mathrm{~K})$ & \\
\hline Latent heat & 420 & {$[44]$} \\
{$[\mathrm{kJ} / \mathrm{kg}]$} & &
\end{tabular}




\subsection{Experimental characterization of single particles and coatings}

In order to verify that simulated splat morphologies match with actual ones, WC-12\%Co and WC17\% Co particles were cold-sprayed with a Kinetics 4000 system from CGT onto smooth surfaces consisting of the same materials. The powders (Figure 2), obtained by agglomeration and sintering, were provided by Fujimi Inc. (Kiyosu, Japan). The size distribution for both agglomerated powders is $-32+10 \mu \mathrm{m}$, with a mean agglomerate size of $20 \mu \mathrm{m}$ and mean WC particle size below $1 \mu \mathrm{m}$. The hardmetal layers onto which cold-spray particles are collected must be sufficiently thick to make sure the underlying substrate is not influencing the particle impact process [46]. Since cold spraying of hardmetals is not yet an optimized technique, HVOF-spraying was employed to confidently obtain such sufficiently thick and dense layers. The same feedstock powders mentioned above were therefore deposited onto carbon steel flat substrates using a DJH2700 equipment from Oerlikon Metco. Coatings were subsequently ground with a Struers TegraPol-11 system using SiC papers and eventually polished with a MetaDi (Buehler) diamond suspension. HVOF process parameters have been previously published in [47], whereas those used for cold gas spraying are the same as previously employed in $[18,23]$ and are listed in Table IV.

Table IV. Cold spray process parameters

\begin{tabular}{|l|l|l|l|l|}
\hline $\begin{array}{l}\text { Powder } \\
\text { composition }\end{array}$ & Gas pressure (bar) & $\begin{array}{l}\text { Gas temperature } \\
\left({ }^{\circ} \mathrm{C}\right)\end{array}$ & $\begin{array}{l}\text { Standoff distance } \\
(\mathrm{mm})\end{array}$ & $\begin{array}{l}\text { Powder feeding } \\
\text { rate }(\mathrm{g} / \mathrm{min})\end{array}$ \\
\hline WC-12Co & 30 & 800 & 10 & 45 \\
\hline WC-17Co & 25 & 800 & 10 & 45 \\
\hline
\end{tabular}

These single-splat samples were observed by scanning electron microscopy (SEM: Nova NanoSEM 450, FEI - ThermoFisher Scientific, Hillsboro, Oregon, USA) on their top surfaces and crosssections. The latter were prepared by cold-mounting the samples in epoxy resin in order to avoid any preparation-related artefact. Mounted samples were cut with a semi-automatic metallographic saw, ground with SiC papers and eventually polished using $3 \mu \mathrm{m}$ polycrystalline diamond suspension and colloidal silica suspension. 


\section{Results and discussion}

\subsection{Static stress-strain relations for WC-12Co and WC-17Co by microstructure-based}

modeling

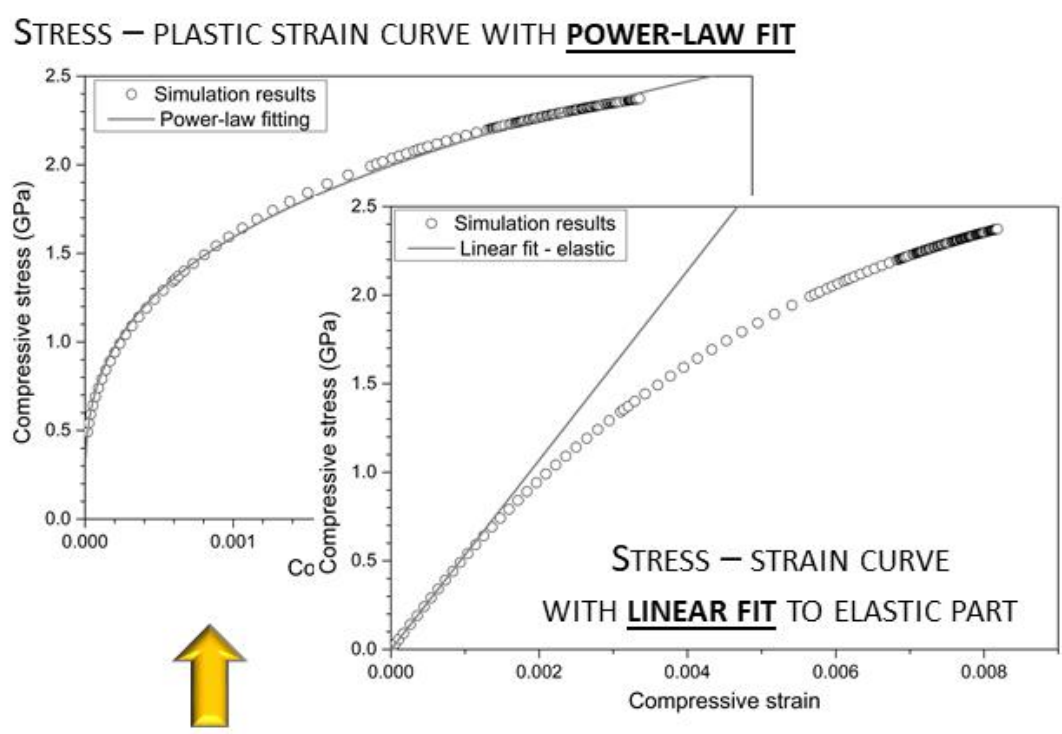

F.E. MESH WITH BOUNDARY CONDITIONS
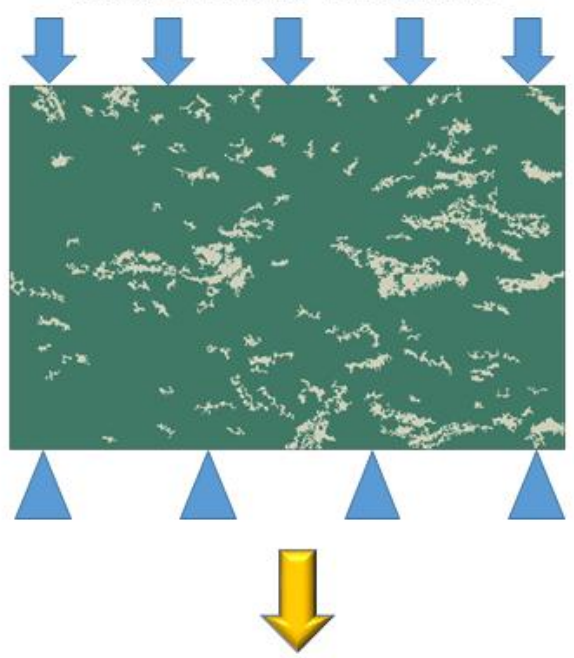

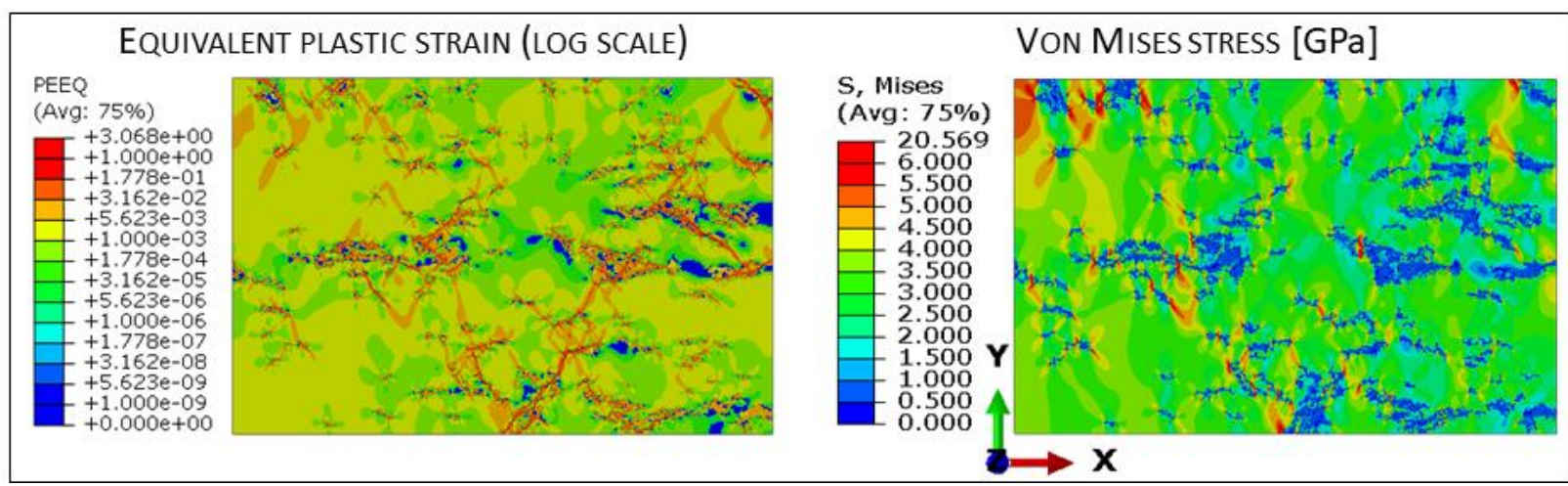

Figure 3. Results of a simulated uniaxial compression test on a WC-17\%Co coating: microstructurebased FE mesh; resulting map of Von Mises stress after compression; extrapolated stress (logarithmic) strain curve with linear fit to the elastic part; stress - plastic strain curve obtained after subtraction of elastic strain component, with power-law fit.

As shown in Figure 3, uniaxial compressive tests allowed extracting the elastic-plastic properties of the dense hardmetal phase. Von Mises stress maps show predictable concentrations in the WC-rich hardmetal regions (see the description given in Section 2.2) next to "Co lakes", due to the significant differences in stiffness and yield strength. This should probably be taken into account in any practical application of the coatings, since cracks could initiate in those overloaded locations, 
e.g. under sliding or abrasive wear conditions. Detailed investigation of these aspects is, however, outside the aims of the present paper and might be considered in future work.

From the model outputs, the logarithmic compressive strain is computed as $\varepsilon=\ln \left(l / l_{0}\right)$, where $l=$ deformed length (measured along the y direction indicated in Figure 3 ) and $l_{0}=$ initial length, and it is plotted against the applied (compressive) stress. The stress-strain curve is linear at low strains, then starts to deviate increasingly from linearity as the material yields. The presence of Von Mises stress concentrations and of resulting differences in the equivalent plastic strain at various locations (Figure 3) suggests that yielding does not begin simultaneously at distinct locations across the microstructure. It is therefore difficult to define a clear elastic limit. Following the usual approach employed with experimental stress-strain curve, the elastic limit is assumed to occur perceivable deviation from linearity occurs, although it has to be kept in mind that yielding might have already started at some isolated points.

From the slope of the linear (elastic) portion of the curve below the elasticity limit, the elastic modulus $(E)$ is obtained. The overall strain above the elastic limit can be decoupled in an elastic and a plastic component: the former is computed as $\varepsilon_{e l}=\sigma / E$ and employed to determine the plastic strain component $\varepsilon_{p}=\varepsilon-\varepsilon_{e l}$. A plot of the stress - plastic strain curve (Figure 3) is fitted with the power-law relation (eq. 3) described in Section 2.2, which corresponds to the static part of the Johnson-Cook constitutive relation (eq. 4). As shown in Sections 2.2 and 2.3, indeed, the strain component to be employed in these equations is the sole plastic component $\varepsilon_{p}$.

For each coating material, the fitted terms $A, B, n$ obtained from each microstructure have been averaged and the results, summarized in Table I and Table II, were employed as input parameters to model the dense hardmetal portion of the powder particles. 


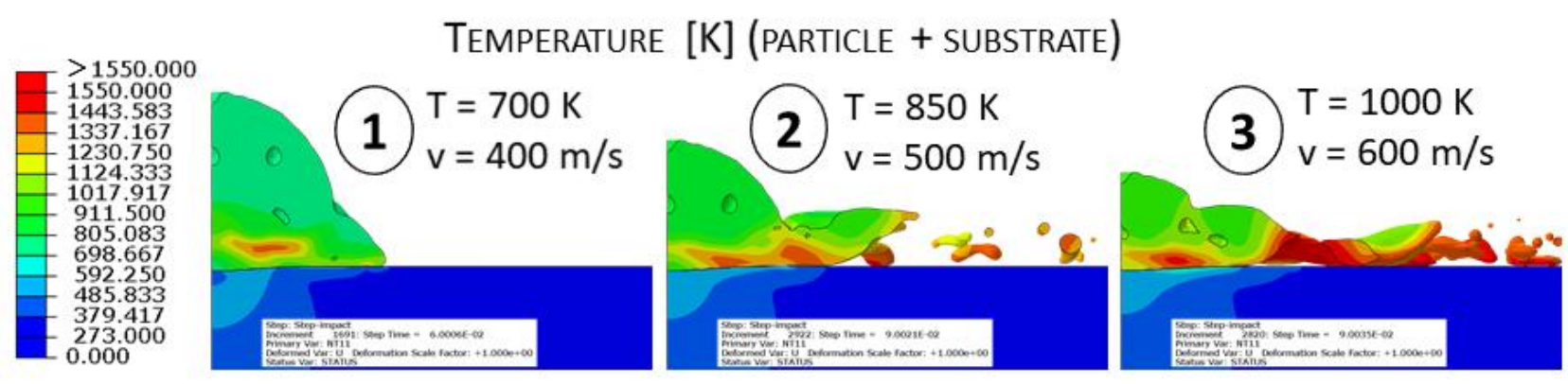

ACCUMULATED FAILURE (PARTICLE)
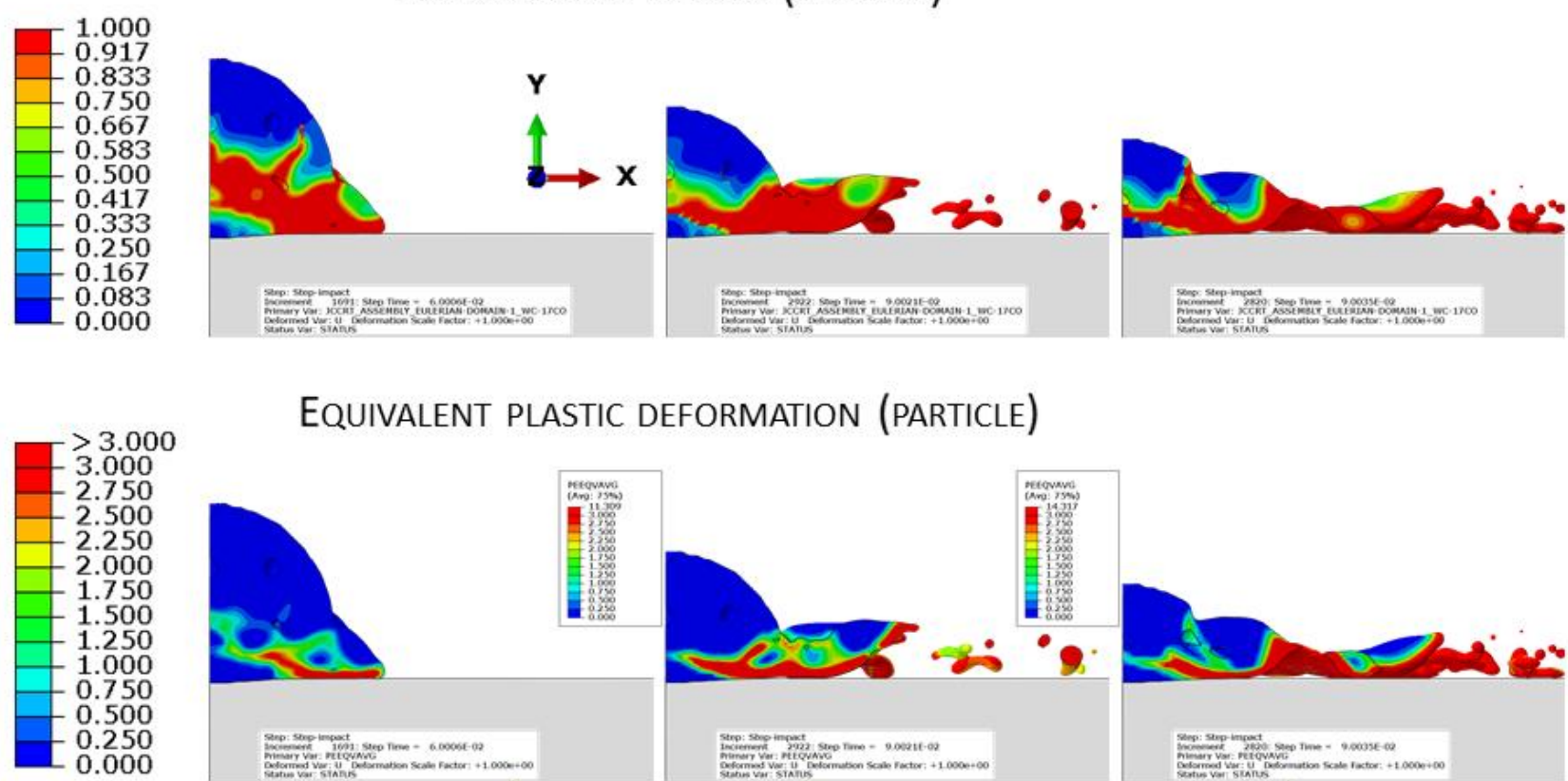

\section{Equivalent PLASTiC DEFORMATION (PARTICLE)}

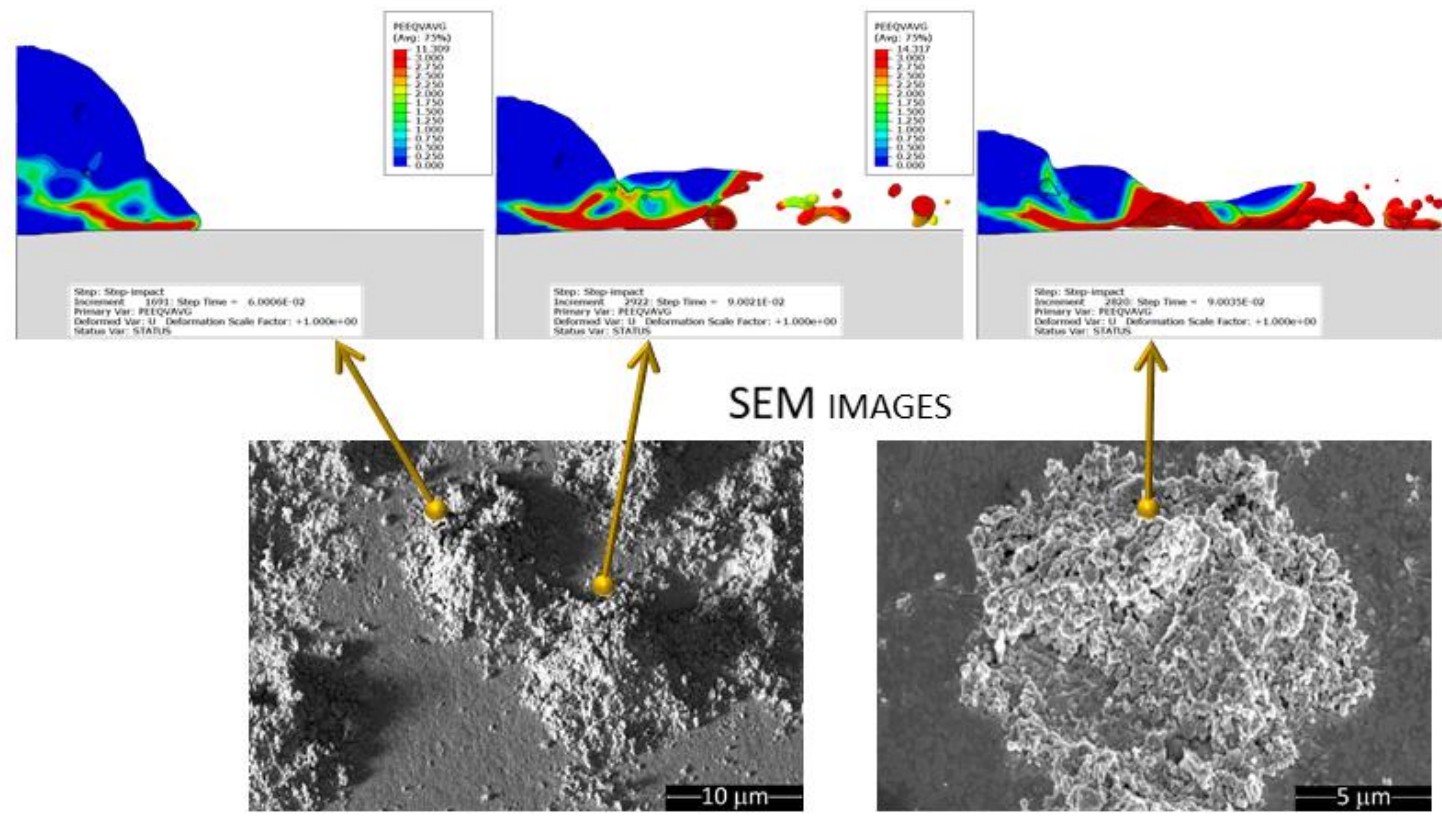

Figure 4. Results of the Lagrangian-Eulerian finite element simulation of the impact of a WC$12 \%$ Co particle onto a smooth WC-12\%Co substrate: maps of system temperature, accumulated failure and equivalent plastic deformation of the particle, and comparison to SEM micrographs. 
TEMPERATURE [K] (PARTICLE + SUBSTRATE)

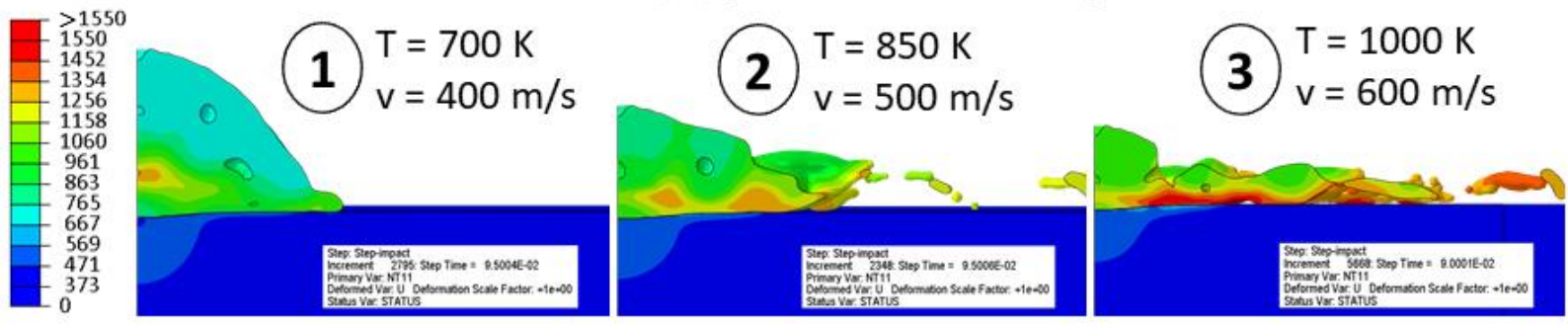

ACCUMUlated failure (PARTICLE)

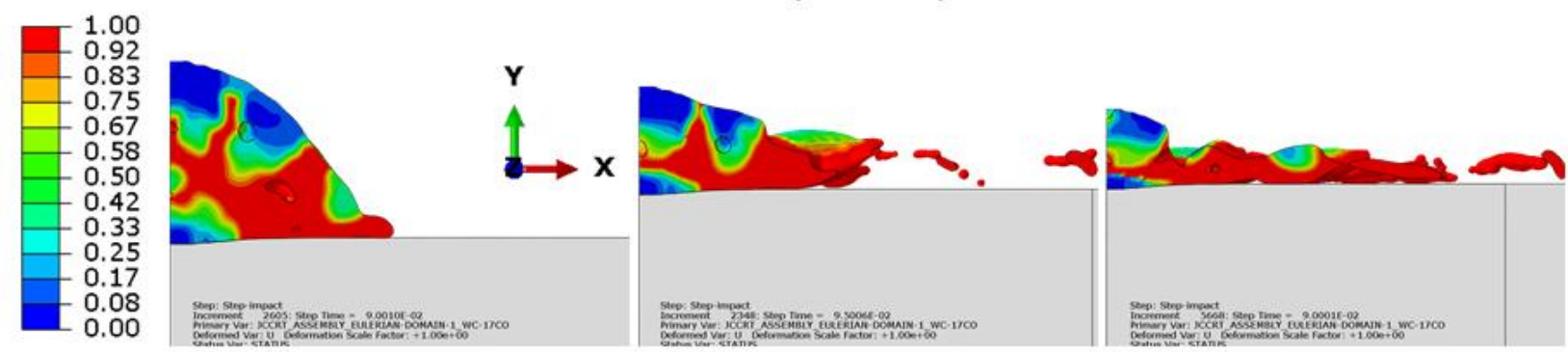

Equivalent PLASTIC DEFormation (PARTICLE)

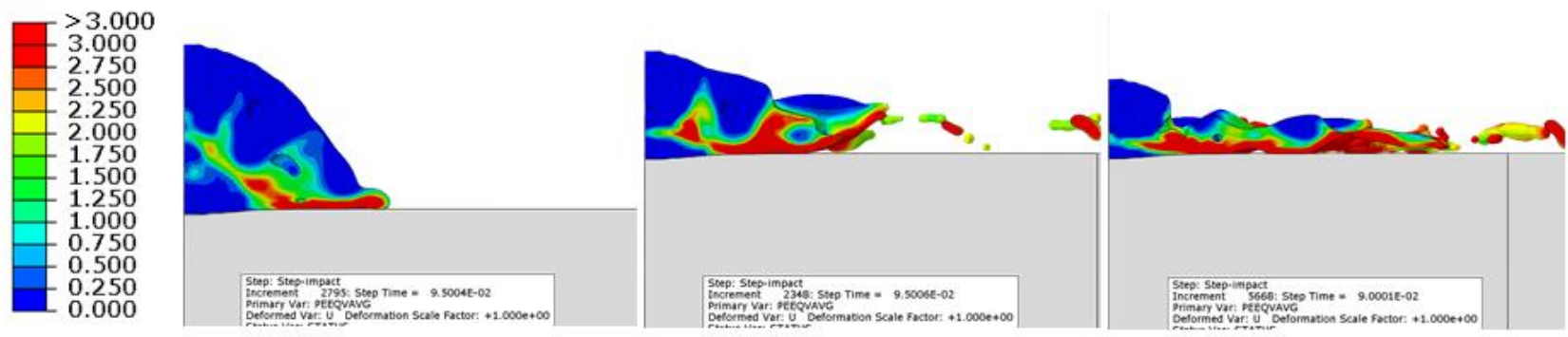

SEM IMAGES
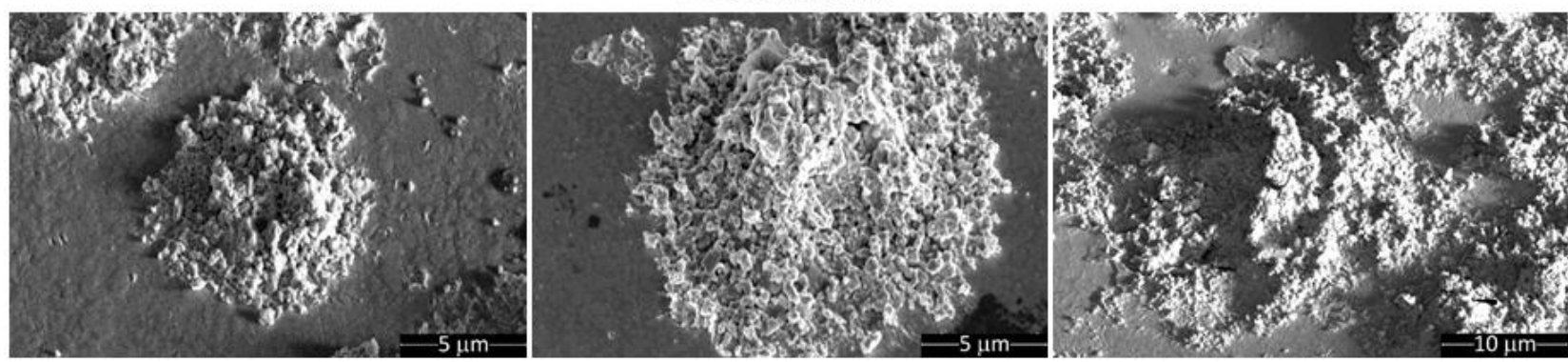

Figure 5. Results of the Lagrangian-Eulerian finite element simulation of the impact of a WC17\% Co particle onto a smooth WC-17\%Co substrate: maps of system temperature, accumulated failure and equivalent plastic deformation of the particle, and comparison to SEM micrographs.

The simulations return similar results for WC-12\% Co (Figure 4) and WC-17\%Co (Figure 5) compositions. In all simulations, flattening is assumed to end when the overall kinetic energy of the particle reaches zero, which normally occurs in $60-95 \mathrm{~ns}$. 
Particle flattening increases as a function of impact velocity and, secondarily, temperature, whereas the underlying hardmetal surface undergoes minimal deformation. Predictably, WC-12\%Co particles tend to flatten slightly less than WC-17\%Co ones do under identical impact conditions. In all cases, anyway, particles consist of a non-flattened central part and a spread-out rim. Increased flattening is associated to a reduction in the volume of the unaffected central area and to a larger, more spread-out rim. It is particularly important to note that failure of the hardmetal plays a key role on deformation and flattening; namely, extensive plastic deformation is associated to areas where the threshold for failure onset (Eq. 6) was exceeded the most, and where subsequent damage accumulation resulted in severe degradation of the material's stiffness.

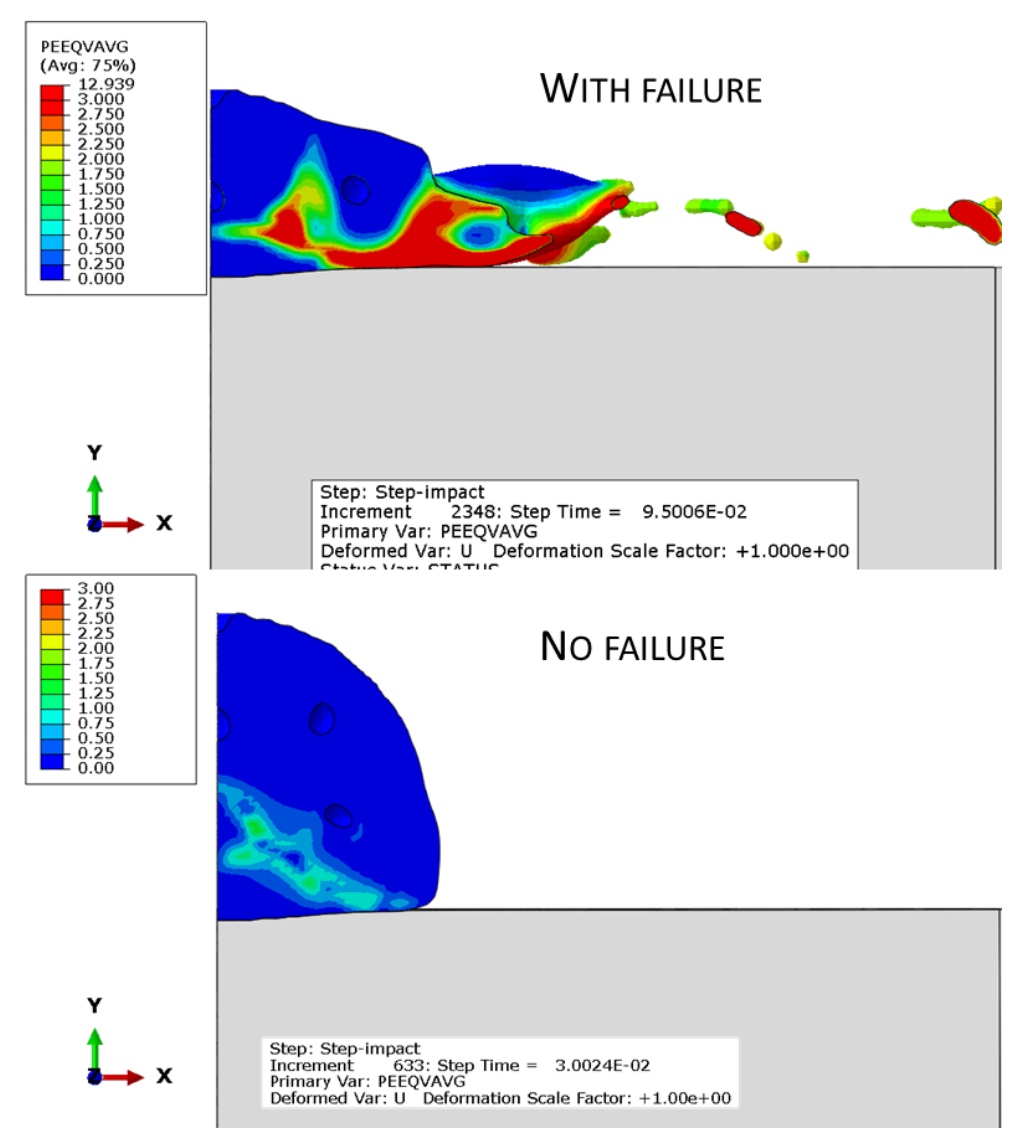

Figure 6. Comparison between the results of Lagrangian-Eulerian simulations of the impact of a WC-17\%Co particle onto polished WC-17\%Co (velocity: $500 \mathrm{~m} / \mathrm{s}$; temperature: $850 \mathrm{~K}$ ), with and without inclusion of material failure (damage initiation and progression criteria).

Maps of accumulated failure in Figure 4 and Figure 5 show values greater than 0 (meaning that some reduction in the stiffness matrix occurred locally as a result of the failure criterion being 
exceeded) and often close or equal to 1 (meaning negligible residual stiffness) where the largest plastic flow occurred. Had no failure criterion been included in the simulation, the particle would have behaved in a much stiffer manner and would have achieved much lower flattening degrees, as shown for instance in Figure 6. To the contrary, the observed morphologies are quite consistent with those observed experimentally by SEM.

Since particle deformation is primarily controlled by failure, exact values of the static stress-strain parameters are not as influential on the model outcome as they would have been in case of a ductile metal particle (as described in [28]). Approximations involved in the derivation of those parameters, such as not accounting explicitly for individual WC grains (see Section 2.2), are therefore expected not to impair significantly the reliability of the model prediction. The link between deformation and failure also implies that flattening is unavoidably associated to the ejection of broken material fragments out of the particle's rim. The higher the impact velocity and temperature of the particle, the larger the particle's flattening degree, and the greater the amount of detached fragments. This numerical prediction is, once again, consistent with the SEM micrographs in Figure 4 and Figure 5, showing ejecta around the most flattened particles. In a previous experimental study, Yin et al. [48] had already proposed a model for the deposition of WC-Co, which acknowledged the important role of particles' fragmentation. That model, however, did not stress the occurrence of deformation and flattening of the WC-Co particles: this might have been due to the fact that the coatings studied in [48] were not pure WC-Co, but (WC-Co)+Ni composites, so that WC-Co particles tended to penetrate into softer Ni splats with less deformation than is observed in the present case, where WC-Co particles impact onto a homologous surface.

It should be remarked that, in a cold-spray process, particles' velocities and temperatures have a stochastic distribution around a mean value. As reported in [23], the average velocity and temperature of the WC-17\%Co particles are $515 \mathrm{~m} / \mathrm{s}$ and $890 \mathrm{~K}$, i.e. quite close to the simulated setting with $500 \mathrm{~m} / \mathrm{s}$ velocity and $850 \mathrm{~K}$ temperature; however, distinct particles can be assumed to acquire different velocity and temperature values around that average, and the same applies to WC- 
$12 \%$ Co particles, the average velocity and temperature of which are $598 \mathrm{~m} / \mathrm{s}$ and $810 \mathrm{~K}$.

Morphologies corresponding to particles impacting at lower as well as at higher velocities and temperatures are therefore experimentally observed by SEM, as shown in Figure 4 and Figure 5. Following the simulated flattening process of a particle impinging at intermediate velocity and temperature (Figure 7), plastic strain is initially $(\mathrm{t}=10 \mathrm{~ns})$ localized in a "shear band" ranging from the edge of the contact area towards the interior, where the maximum temperature increase also occurs (Figure 8).
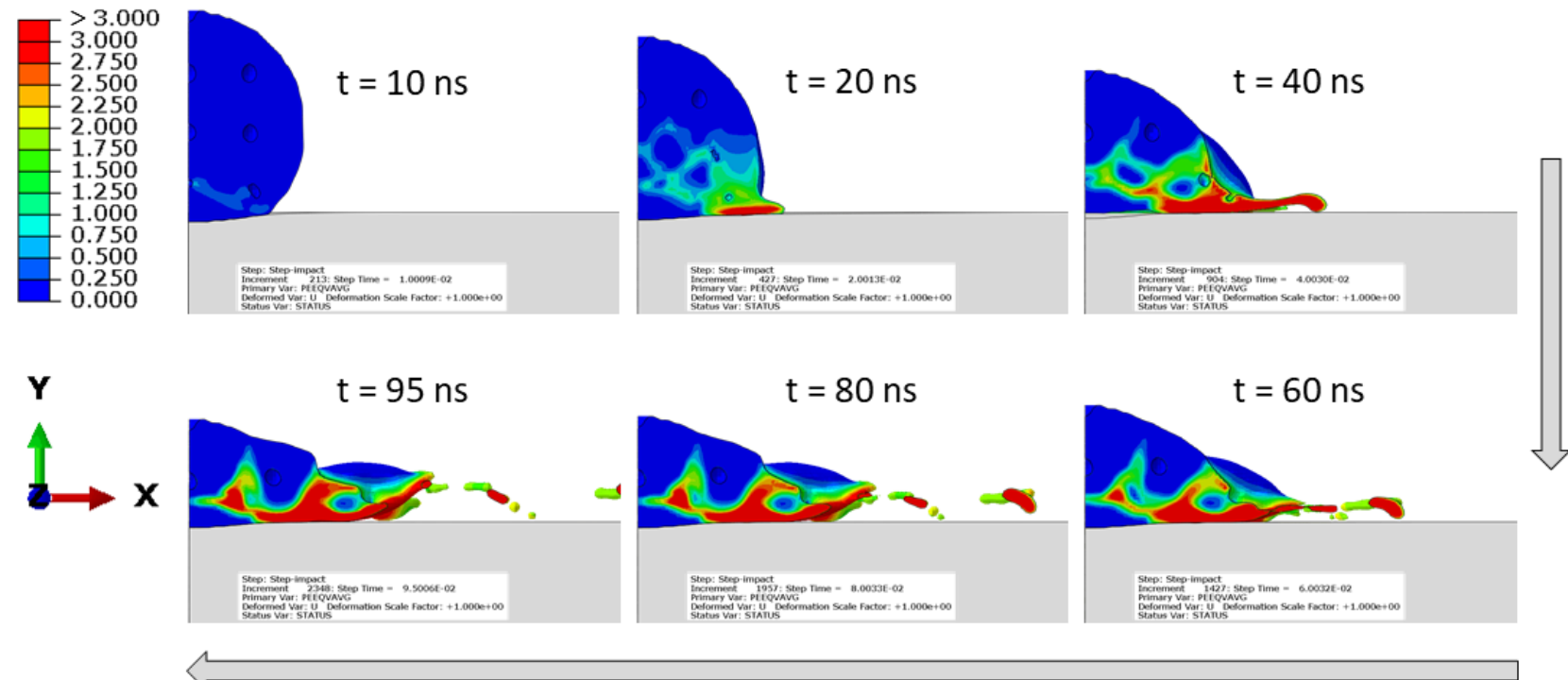

Figure 7. Simulated progression of the flattening of a WC-17\%Co particle impacting at $500 \mathrm{~m} / \mathrm{s}$, $850 \mathrm{~K}$ : equivalent plastic strain maps up to maximum flattening. Arrows indicate the time sequence of the images.

Temperatures become very close to or even higher than the solidus temperature (taken as the solidus temperature of the metal matrix: $1580 \mathrm{~K}$, see Table I and Table II). In such a softened region, pores are readily closed, which indicates effective inner densification of the particle where plastic deformation is large. The topmost section of the particle, to the contrary, remains quite unaffected and retains its original porosity.

As time progresses $(t=20-40 \mathrm{~ns})$, temperature increases also at the contact edge. Once again, the temperature reaches levels close to or above the solidus temperature; hence, plastic flow and 
associated material failure become particularly extensive in the contact edge area (Figure 7) and spreading out of the rim begins. Splashed "fingers" around a flattened particle do convey practical evidence that a limited amount of liquid phase was indeed developed in the metal matrix, at the bottom face of the rim, where temperatures are predicted to be the highest (Figure 9). Spreading continues even when local temperatures decrease somewhat (Figure 8), because the material has meanwhile been weakened by failure associated to the extensive plastic flow; hence, its stiffness has been greatly reduced. As a result, fragmentation of the outermost portion of the rim occurs $(\mathrm{t} \geq$ $60 \mathrm{~ns})$ as mentioned previously.

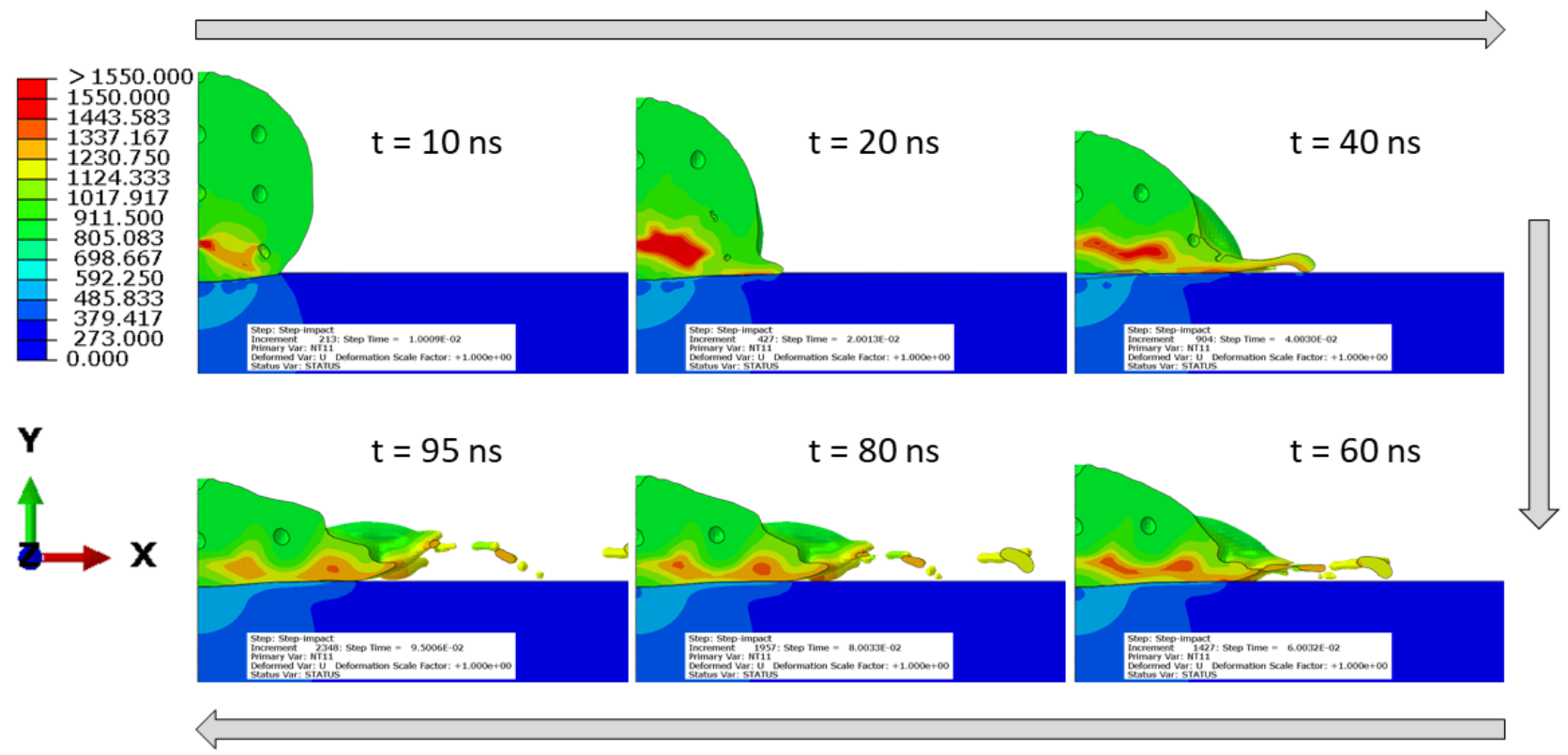

Figure 8. Simulated progression of the flattening of a WC-17\% Co particle impacting at $500 \mathrm{~m} / \mathrm{s}$, $850 \mathrm{~K}$ : temperature maps (unit: K) up to maximum flattening. Arrows indicate the time sequence of the images.

Since, on the particle's bottom face, the largest plastic strain and greatest temperature rise occur in the rim, that is the region where preferential bonding to the substrate is expected. On the other hand, little bonding is expected in the center of the contact area, where temperature rise and plastic strain are minimal (Figure 7, Figure 8). This behavior is common to many cold sprayed materials, including ductile metals and metallic glasses $[49,50]$. 
Overall, the models point out to a considerable difference between the plastically deformed rim and the center of the particle: the latter achieves limited interface bonding and, in its upper section, is also incompletely densified. It is therefore reasonable to expect that the center of the particle might detach from the rim and bounce off the substrate during elastic recovery.

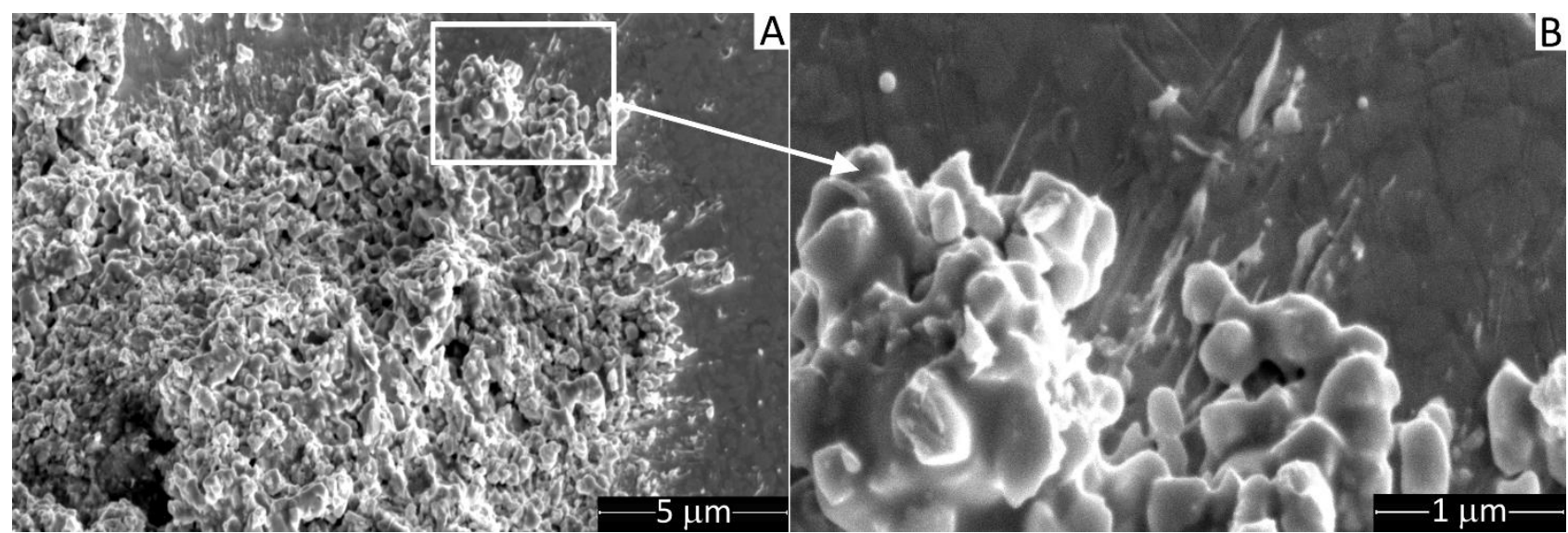

Figure 9. SEM micrographs showing an extensively flattened WC-17\%Co particle onto polished WC-17\% Co substrate: overview (A) and detail of the marked area (B), showing projection of molten Co fingers.

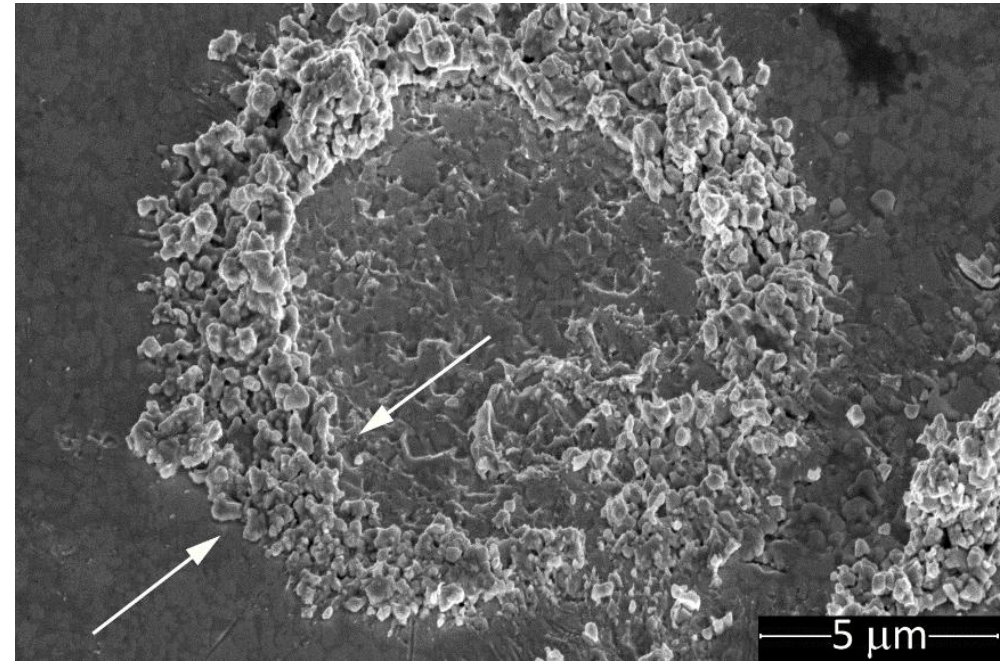

Figure 10. SEM micrograph showing the impression left by a rebounded WC-12\%Co particle sprayed onto polished WC-12\% Co, which only left a residual rim attached (arrows). 


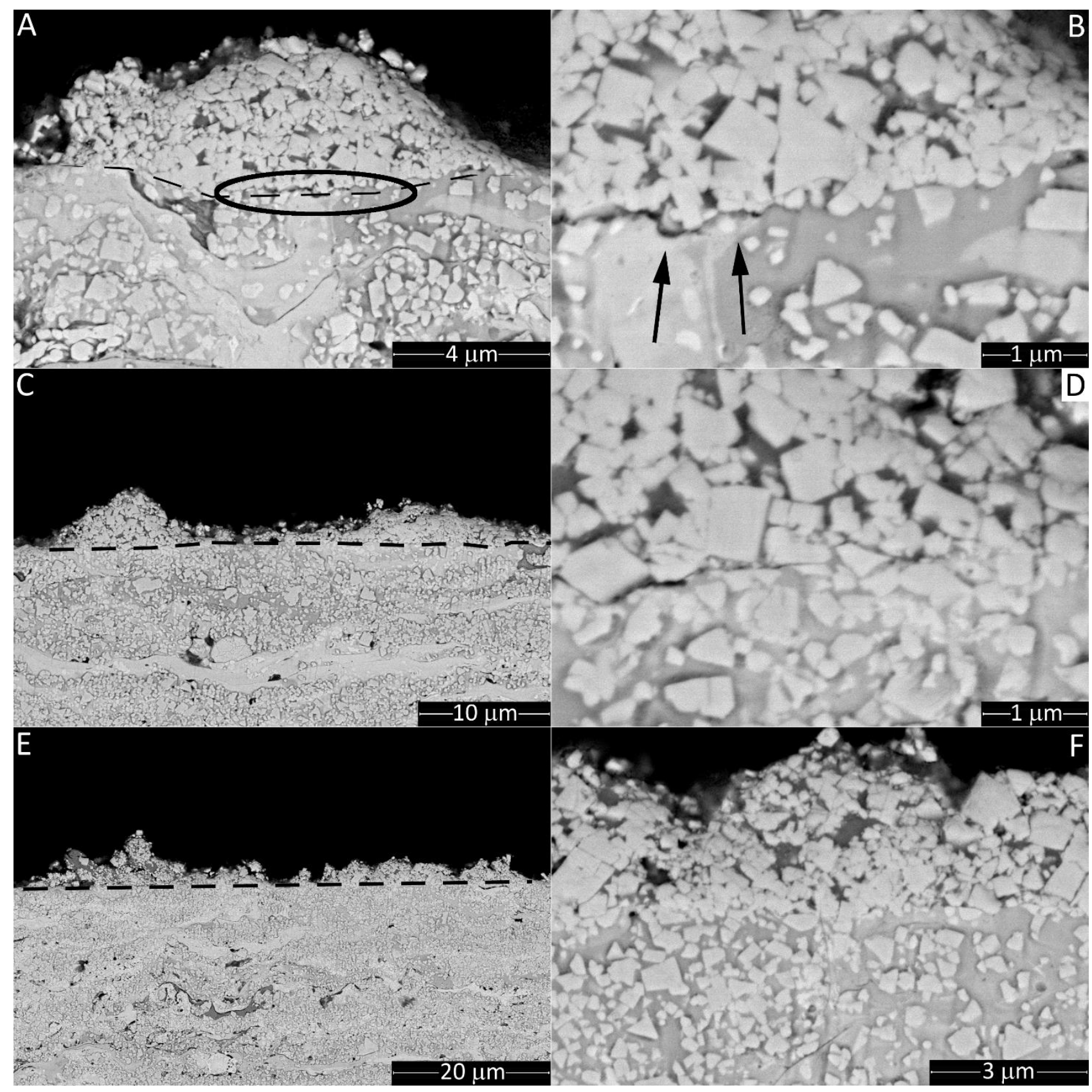

Figure 11. Cross-sectional SEM micrographs of WC-17\%Co particles deposited onto polished WC$17 \%$ Co substrate.

A, C, E: low-magnification overviews (dashed lines = interface; circle in panel A = poorly bonded region)

B, D, F: high-magnification details of interface areas (arrows in panel A = poorly bonded area).

Figure 10 accordingly shows an impact trace produced by a rebounded particle that left an attached rim (see arrows). Even clearer evidence comes from the cross-sectional SEM micrographs in Figure 11. Specifically, Figure 11A depicts a small particle, impacting with low momentum: this situation 
is similar to that of a larger ( $30 \mu \mathrm{m}$ diameter) particle impacting at relatively low speed as in condition (1) of Figure 5; accordingly, the observed shape is not too dissimilar from the modeled one and, consistent with the prediction, good bonding is achieved along the rim, whilst an interface gap exists in the center (see circle). Figure 11C,E show larger particles, which left a tightly adherent rim whilst the center bounced off.

Details of the interface regions in Figure 11B,D,F shows that heating and plastic deformation of the impacting particle in the rim area resulting in tight interface bonding by producing two mechanisms:

1) The heated and deformed matrix attached firmly to the underlying material, bonding both to the homologous metallic phase on the substrate surface and to the carbide phase. Excellent wettability between Co and WC is indeed one of the very reasons that confer WC-Co hardmetals their excellent combination of hardness and toughness;

2) The WC grains contained in the impinging particle, energetically dragged by the extensive plastic flow of the matrix, penetrate into the substrate surface, achieving mechanical anchoring and perhaps developing some form of metallurgical bonding to the matrix phase, once again because of the mentioned wettability.

Limited deformation and little damage are visible on (Figure 10) and below (Figure 11) the substrate surface, which is also consistent with the model's predictions in Figure 5.

\subsection{The role of porosity on flattening}

The role of porosity within a particle is summarized by the simulation results in Figure 12 . The shape of the dense WC-17\%Co particle is not too different from that of the porous one and its flattening process follows the same trend described above, with a relatively non-deformed particle center, an extensively deformed rim showing having higher chances for better interface bonding, and ejections of material out of the rim itself. The transition between the non-deformed center and 
the spread-out rim becomes, however, sharper; plastic flow is more localized in the rim only, which is a consequence of the greater stiffness of the dense particle as compared to the porous one. It is, therefore, more likely for the particle or, at least, its central portion to rebound. Moreover, it looks like bigger fragments of material are ejected from the particle, which is also a consequence of the extreme stretching experienced by the deformed rim with respect to the center.

All of these considerations are consistent with the practical observation of very low deposition efficiencies when trying to process dense WC-Co particles by cold spraying.

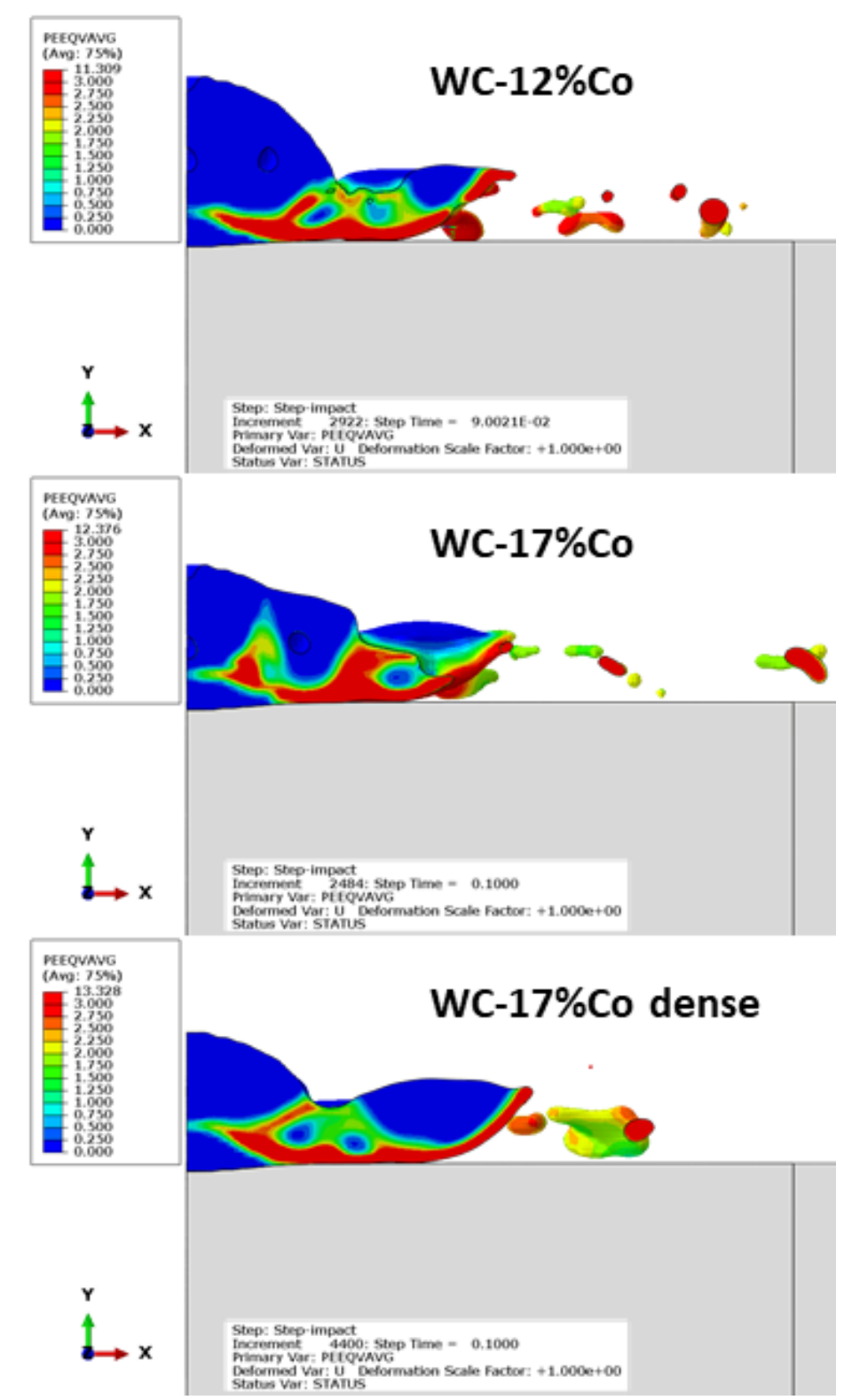

Figure 12. Comparison between the simulated impacts of a porous WC-12\%Co particle, a porous WC-17\%Co particle and a dense WC-17\%Co particle (velocity: $500 \mathrm{~m} / \mathrm{s}$; temperature: $850 \mathrm{~K}$ ). In all cases, the substrate consists of the same material as the particle. 


\subsection{Flattening and energy balance}

A

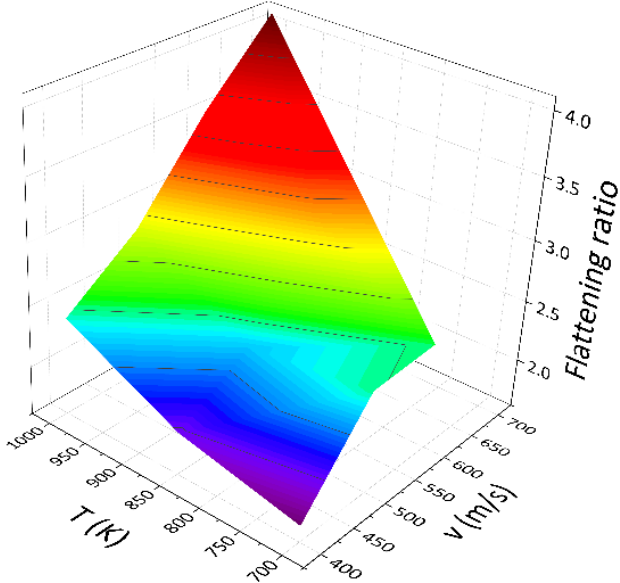

C

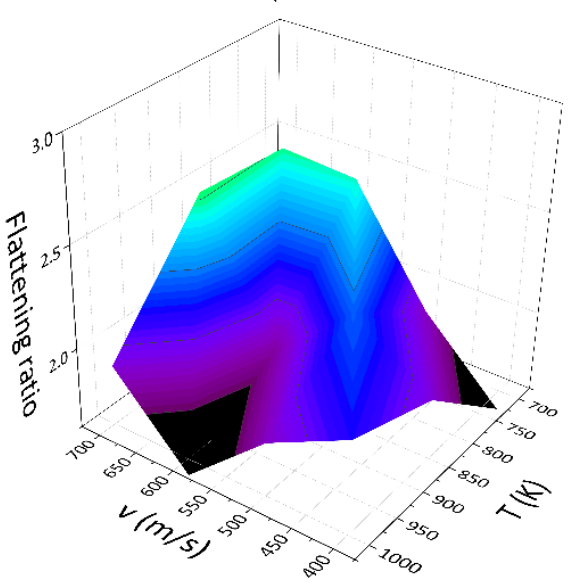

B

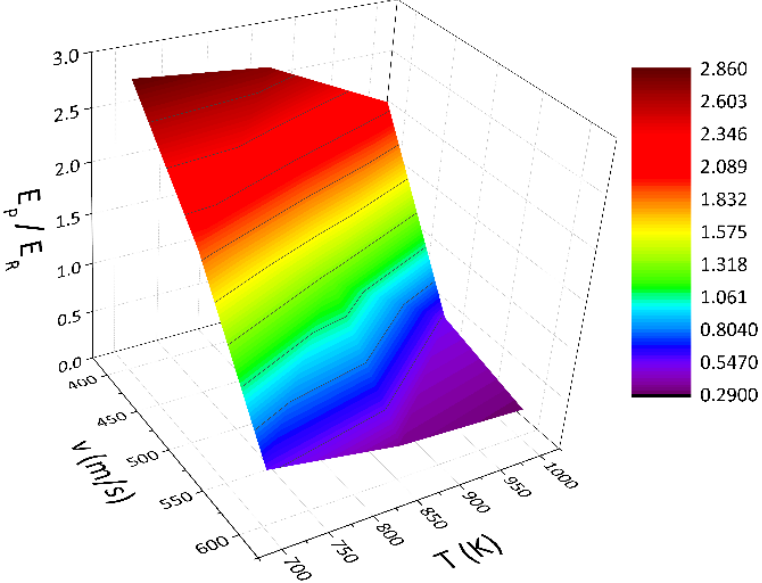

D

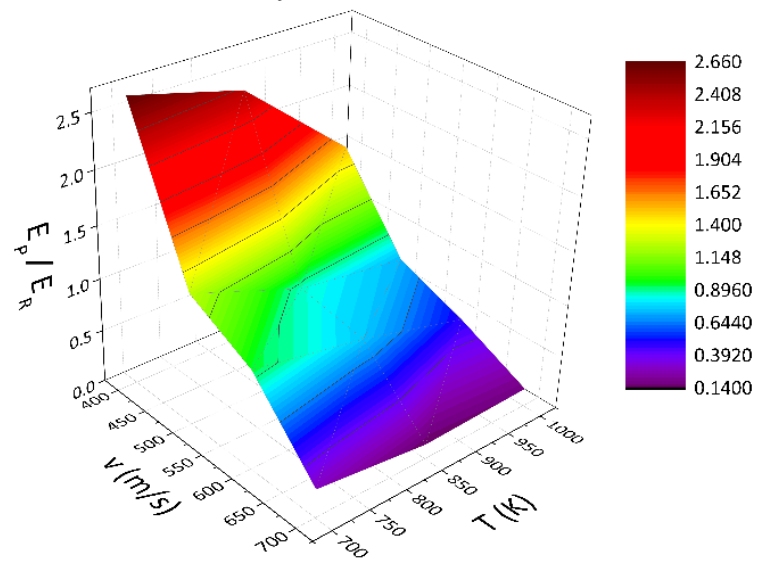

Figure 13. Plots of particle flattening ratio $(A, C)$ and $E_{P} / E_{R}$ energy ratio $(B, D)$ for $W C-17 \%$ Co $(\mathrm{A}, \mathrm{B})$ and $\mathrm{WC}-12 \% \mathrm{Co}(\mathrm{C}, \mathrm{D})$ particles impacting onto homologous polished substrate at various initial velocities and temperatures.

The above discussions highlight a known issue of cold spraying, namely the need for an impinging particle to develop sufficient interface adhesion (and, in case of an initially porous particle such as the present ones, sufficient internal cohesion as well) in order to resist the rebound force generated by the release of the elastic strain accumulated during impact [51]. Along with promoting inner densification and interface bonding, plastic deformation of the particle also has the additional role of dissipating part of the initial kinetic energy, reducing the fraction that is elastically stored in the system and later available for rebounding. The present authors, for instance, showed that the ratio between the energy dissipated by plastic deformation in the particle $\left(\mathrm{E}_{\mathrm{P}}\right)$ and the elastic deformation energy stored in both the particle and the substrate at the end of the flattening process (i.e. when the 
kinetic energy of the particle is zero, as mentioned at the beginning of the Section), also called rebound energy $\left(E_{R}\right)$, is a useful predictor of the deposition efficiency of CS metallic glasses [52]. The same $\mathrm{E}_{\mathrm{P}} / \mathrm{E}_{\mathrm{R}}$ ratio was therefore computed in the present case and it is plotted as a function of impact velocity and temperature in Figure 13B,D, together with the particle flattening ratio, i.e. the ratio between the maximum radius of the flattened particle and the initial value (Figure 13A,C). The flattening ratio of WC-17\%Co particles increases primarily as a function of particle velocity and, secondarily, temperature. Higher initial kinetic energy indeed leads to larger plastic deformation and more extensive failure; additionally, higher initial temperature promotes slightly better plasticity according to the Johnson-Cook model (Eq. 4).

The kinetic energy of the particle, however, increases even faster than does plastic dissipation; therefore, as the impact velocity increases, an ever greater amount of energy is reversibly stored through elastic strain, i.e. the $\mathrm{E}_{\mathrm{P}} / \mathrm{E}_{\mathrm{R}}$ ratio decreases with increasing impact velocity (Figure $13 \mathrm{~B}, \mathrm{D}$ ). This exerts an opposite effect on the particle's deposition behavior, as compared to the increase in flattening ratio. Greater flattening, as discussed previously, favors the adhesion of the particle by promoting its inner densification and interface bonding; a greater fraction of reversibly stored elastic strain energy, to the contrary, promotes rebounding.

Deriving a quantitative relation or a parameter to predict the expected deposition efficiency is not possible at present, since it is not known precisely how flattening and equivalent plastic strain in the particle are related to its bonding strength. It is, however, reasonable to expect that efficiency cannot increase linearly with velocity: whilst an excessively low particle velocity (i.e. excessively low impact momentum) would not produce enough plastic flow to achieve practical bonding, excessively high velocity (momentum), on the other hand, causes too much rebounding, probably resulting in inefficient deposition even though interface bonding is promoted. The largely fractured particles seen in Figure 10 and Figure 11C-F are indeed evidence to a considerable loss of material in spite of good interface bonding along the rim. 
In the case of $\mathrm{WC}-12 \% \mathrm{Co}$, the flattening ratio even drops at very high velocities (Figure 13C). This seemingly inconsistent finding is related to the fact that, at high velocity (high momentum), failure of this stiffer, more brittle material becomes so extensive that significant portions of the flattened rim are ejected out of the particle and not accounted for in calculating the flattening ratio. This means it is even more difficult to achieve efficient deposition of WC-12\%Co than it is for WC$17 \% \mathrm{Co}$, since trying to promote bonding of $\mathrm{WC}-12 \%$ Co particles by conferring them higher momentum can result in their severe fragmentation.

All of the above considerations indicate that cold spray deposition of hardmetals can hardly be a very efficient process, at least within the range of deposition conditions that are technologically attainable at present. Accordingly, deposition efficiencies of $\mathrm{WC}-17 \mathrm{Co}$ and $\mathrm{WC}-12 \mathrm{Co}$ powders in the current cold gas spray process were $21 \%$ and $14 \%$, respectively. Practical implementations of this process should therefore focus on high added-value applications in particularly severe environments, where the excellent performances of CS coatings, which feature a unique combination of high denseness and no decarburization, offset their presumably high cost.

\section{Conclusions}

The build-up mechanisms of cold sprayed WC-Co coatings were investigated by simulating the impact of porous WC-12wt.\%Co and WC-17wt.\%Co particles onto homologous, smooth surfaces. The simulations were validated by SEM observation of cold-sprayed WC-12Co and WC-17Co particles deposited onto a homologous, smooth hardmetal surface.

A coupled Eulerian-Lagrangian, three-dimensional finite element model was set up, whereby the porous particle was tracked within a Eulerian domain whereas the substrate was simulated as a Lagrangian body. The static plasticity parameters for the constitutive models of WC-12\%Co and WC-17\% Co hardmetals were, in turn, obtained by micro-scale finite element simulations of 
compression tests on the actual microstructures of the corresponding materials, since direct experimental measurement through compression testing of powder particles would have been impractical.

Simulations and experiments consistently show that particles flatten onto an underlying hardmetal surface that experiences little deformation. Specifically, shortly after contact with the substrate, the bottom region of the particle undergoes compaction and spreads out into an extensively deformed rim, whereas the upper region remains mostly unaffected and retains its porosity.

Ductile failure of the hardmetal plays a key role in compaction and spreading. If failure onset and damage progression are not included in the constitutive model of the hardmetal, the eventual morphology of the particle is inconsistent with the experimental observations, because the predicted deformation is insufficient.

As the rim spreads, its bottom face experiences heating, close to or even above the melting point of the matrix, and develops large equivalent plastic strain, whereas little deformation and heating are seen in the middle of the contact surface. Limited adhesion is therefore produced in the center of the contact area, whereas the deformed rim can bond to the underlying surface through two mechanisms:

1) Metallurgic bonding of the deformed and softened metal matrix to the underlying hardmetal surface;

2) Mechanical fixation of the hard WC grains, which indent the underlying material while being dragged along by the flowing matrix.

Since the plastic flow of the rim involves extensive failure, it ejects material fragments during its spreading process, as confirmed experimentally.

Increasing the momentum of the particle enhances the spreading and deformation of the rim, which promotes stronger bonding to the underlying surface. On the other hand, bigger fragments are ejected; moreover, a larger amount of kinetic energy is stored into elastic deformation of the 
system, which may cause rebounding of the whole particle or, at least, of its poorly bonded central portion. It is therefore inferred that the deposition efficiency of hardmetal particles does not increase linearly with impact velocity, since rebounding and fragmentation could offset the benefits of enhanced flattening at higher velocity.

Stiffening of the particle, resulting from lower porosity or from intrinsic material properties (as it occurs e.g. for $\mathrm{WC}-12 \mathrm{Co}$ in comparison to $\mathrm{WC}-17 \mathrm{Co}$ ), produces even more inhomogeneous deformation, with a greater dichotomy between the spread-out rim and the undeformed center. This may further promote severe fragmentation and/or rebounding of the center, thus negatively affecting the deposition efficiency.

\section{Acknowledgements}

The authors wish to thank the University of Barcelona for financial support for this research and the Generalitat de Catalunya for the financial support of project 2017SGR1777.

\section{References}

[1] T. Stoltenhoff, H. Kreye, H.J. Richter, An Analysis of the Cold Spray Process and Its Coatings, J. Therm. Spray Technol. 11 (2002) 542-550. doi:10.1361/105996302770348682.

[2] A. Papyrin, V. Kosarev, S. Klinkov, A. Alkimov, V. Fomin, High-velocity interaction of particles with the substrate. Experiment and modeling, in: Cold Spray Technol., Elsevier, 2007: pp. 33-118. doi:http://dx.doi.org/10.1016/B978-008045155-8/50002-8.

[3] T. Schmidt, H. Assadi, F. Gärtner, H. Richter, T. Stoltenhoff, H. Kreye, T. Klassen, From particle acceleration to impact and bonding in cold spraying, J. Therm. Spray Technol. 18 (2009) 794-808. doi:10.1007/s11666-009-9357-7.

[4] T. Hussain, D.G. McCartney, P.H. Shipway, D. Zhang, Bonding mechanisms in cold spraying: The contributions of metallurgical and mechanical components, J. Therm. Spray 
Technol. 18 (2009) 364-379. doi:10.1007/s11666-009-9298-1.

[5] H. Assadi, F. Gärtner, T. Stoltenhoff, H. Kreye, Bonding mechanism in cold gas spraying, Acta Mater. 51 (2003) 4379-4394. doi:10.1016/S1359-6454(03)00274-X.

[6] T. Han, Z. Zhao, B.A. Gillispie, J.R. Smith, Effects of Spray Conditions on Coating Formation by the Kinetic Spray Process, J. Therm. Spray Technol. 14 (2005) 373-383. doi:10.1361/105996305X59369.

[7] D. Lahiri, P.K. Gill, S. Scudino, C. Zhang, V. Singh, J. Karthikeyan, N. Munroe, S. Seal, A. Agarwal, Cold sprayed aluminum based glassy coating: Synthesis, wear and corrosion properties, Surf. Coatings Technol. 232 (2013) 33-40. doi:10.1016/j.surfcoat.2013.04.049.

[8] T. Schmidt, F. Gärtner, H. Assadi, H. Kreye, Development of a generalized parameter window for cold spray deposition, Acta Mater. 54 (2006) 729-742. doi:10.1016/j.actamat.2005.10.005.

[9] G. Bae, S. Kumar, S. Yoon, K. Kang, H. Na, H.-J. Kim, C. Lee, Bonding features and associated mechanisms in kinetic sprayed titanium coatings, Acta Mater. 57 (2009) 56545666. doi:10.1016/j.actamat.2009.07.061.

[10] G. Bae, Y. Xiong, S. Kumar, K. Kang, C. Lee, General aspects of interface bonding in kinetic sprayed coatings, Acta Mater. 56 (2008) 4858-4868. doi:10.1016/j.actamat.2008.06.003.

[11] H. Assadi, H. Kreye, F. Gärtner, T. Klassen, Cold spraying - A materials perspective, Acta Mater. 116 (2016) 382-407. doi:10.1016/j.actamat.2016.06.034.

[12] G. Bae, J. Jang, C. Lee, Correlation of particle impact conditions with bonding, nanocrystal formation and mechanical properties in kinetic sprayed nickel, Acta Mater. 60 (2012) 35243535. doi:10.1016/j.actamat.2012.03.001.

[13] Y. Zou, W. Qin, E. Irissou, J.-G. Legoux, S. Yue, J.A. Szpunar, Dynamic recrystallization in the particle/particle interfacial region of cold-sprayed nickel coating: Electron backscatter diffraction characterization, Scr. Mater. 61 (2009) 899-902. 
doi:10.1016/j.scriptamat.2009.07.020.

[14] M. Hassani-Gangaraj, D. Veysset, V.K. Champagne, K.A. Nelson, C.A. Schuh, Adiabatic shear instability is not necessary for adhesion in cold spray, Acta Mater. 158 (2018) 430 439. doi:10.1016/j.actamat.2018.07.065.

[15] H. Assadi, F. Gärtner, T. Klassen, H. Kreye, Comment on 'Adiabatic shear instability is not necessary for adhesion in cold spray,' Scr. Mater. 162 (2019) 512-514. doi:10.1016/j.scriptamat.2018.10.036.

[16] M. Hassani-Gangaraj, D. Veysset, V.K. Champagne, K.A. Nelson, C.A. Schuh, Response to Comment on "Adiabatic shear instability is not necessary for adhesion in cold spray," Scr. Mater. 162 (2019) 515-519. doi:10.1016/j.scriptamat.2018.12.015.

[17] H. Assadi, T. Schmidt, H. Richter, J.-O. Kliemann, K. Binder, F. Gärtner, T. Klassen, H. Kreye, On Parameter Selection in Cold Spraying, J. Therm. Spray Technol. 20 (2011) 11611176. doi:10.1007/s11666-011-9662-9.

[18] M. Couto, S. Dosta, J.M. Guilemany, Comparison of the mechanical and electrochemical properties of WC-17 and 12Co coatings onto A17075-T6 obtained by high velocity oxy-fuel and cold gas spraying, Surf. Coatings Technol. 268 (2015) 180-189. doi:10.1016/j.surfcoat.2014.04.034.

[19] S. Dosta, M. Couto, J.M. Guilemany, Cold spray deposition of a WC-25Co cermet onto A17075-T6 and carbon steel substrates, Acta Mater. 61 (2013) 643-652. doi:10.1016/j.actamat.2012.10.011.

[20] M. Couto, S. Dosta, M. Torrell, J. Fernández, J.M. Guilemany, Cold spray deposition of WC17 and 12Co cermets onto aluminum, Surf. Coatings Technol. 235 (2013) 54-61. doi:10.1016/j.surfcoat.2013.07.011.

[21] C. Verdon, A. Karimi, J.L. Martin, Microstructural and analytical study of thermally sprayed WC-Co coatings in connection with their wear resistance, Mater. Sci. Eng. A. 234-236 (1997) 731-734. doi:10.1016/S0921-5093(97)00377-8. 
[22] D.E. Wolfe, T.J. Eden, J.K. Potter, A.P. Jaroh, Investigation and characterization of $\mathrm{Cr}_{3} \mathrm{C}_{2}$ based wear-resistant coatings applied by the cold spray process, J. Therm. Spray Technol. 15 (2006) 400-412. doi:10.1361/105996306X124400.

[23] S. Dosta, G. Bolelli, A. Candeli, L. Lusvarghi, I.G. Cano, J.M. Guilemany, Plastic deformation phenomena during cold spray impact of WC-Co particles onto metal substrates, Acta Mater. 124 (2017) 173-181. doi:10.1016/j.actamat.2016.11.010.

[24] R. Fernandez, B. Jodoin, Effect of Particle Morphology on Cold Spray Deposition of Chromium Carbide-Nickel Chromium Cermet Powders, J. Therm. Spray Technol. 26 (2017) 1356-1380. doi:10.1007/s11666-017-0580-3.

[25] S. Kamnis, S. Gu, Study of In-Flight and Impact Dynamics of Nonspherical Particles from HVOF Guns, J. Therm. Spray Technol. 19 (2010) 31-41. doi:10.1007/s11666-009-9382-6.

[26] S. Kamnis, S. Gu, M. Vardavoulias, The Influence of Powder Porosity on the Bonding Mechanism at the Impact of Thermally Sprayed Solid Particles, Metall. Mater. Trans. A. 41 (2010) 3517-3524. doi:10.1007/s11661-010-0488-8.

[27] S. Kamnis, S. Gu, T.J. Lu, C. Chen, Numerical modeling the bonding mechanism of HVOF sprayed particles, Comput. Mater. Sci. 46 (2009) 1038-1043. doi:10.1016/j.commatsci.2009.05.009.

[28] H. Assadi, I. Irkhin, H. Gutzmann, F. Gärtner, M. Schulze, M. Villa Vidaller, T. Klassen, Determination of plastic constitutive properties of microparticles through single particle compression, Adv. Powder Technol. 26 (2015) 1544-1554. doi:10.1016/j.apt.2015.08.013.

[29] A.C.E. Reid, R.C. Lua, R.E. Garcia, V.R. Coffman, S.A. Langer, Modelling Microstructures with OOF2, Int. J. Mater. Prod. Technol. 35 (2009) 361-373. doi:10.1504/IJMPT.2009.025687.

[30] A.E. Johnson, Technical Note 3309: Mechanical Properties at Room Temperature of Four Cermets of Tungsten Carbide with Cobalt Binder, Washington D.C., USA, 1954. http://hdl.handle.net/2060/19930084055. 
[31] N.S. Ottosen, M. Ristinmaa, Introduction to Time-Dependent Material Behavior, in: Mech. Const. Model., Elsevier, 2005: pp. 357-386. doi:10.1016/B978-008044606-6/50014-X.

[32] C. Moosbrugger, ed., Atlas of stress-strain curves, Second Edi, ASM International, Materials Park, OH, USA, 2002.

[33] K. Thomas, A contribution to the study of cold gas dynamic spraying of copper: Influence of the powder characteristics on the mechanical properties of the coating, Universite Libre de Bruxelles, 2007. http://difusion.ulb.ac.be/vufind/Record/ULBDIPOT:oai:dipot.ulb.ac.be:2013/210632/Holdings.

[34] W.Y. Li, M. Yu, F.F. Wang, S. Yin, H.L. Liao, A generalized critical velocity window based on material property for cold spraying by eulerian method, J. Therm. Spray Technol. 23 (2014) 557-566. doi:10.1007/s11666-013-0023-8.

[35] A. Moridi, S.M. Hassani-Gangaraj, M. Guagliano, A hybrid approach to determine critical and erosion velocities in the cold spray process, Appl. Surf. Sci. 273 (2013) 617-624. doi:10.1016/j.apsusc.2013.02.089.

[36] T.S. Price, P.H. Shipway, D.G. McCartney, E. Calla, D. Zhang, A method for characterizing the degree of inter-particle bond formation in cold sprayed coatings, J. Therm. Spray Technol. 16 (2007) 566-570. doi:10.1007/s11666-007-9070-3.

[37] F.F. Wang, W.Y. Li, M. Yu, H.L. Liao, Prediction of Critical Velocity During Cold Spraying Based on a Coupled Thermomechanical Eulerian Model, J. Therm. Spray Technol. 23 (2014) 60-67. doi:10.1007/s11666-013-0009-6.

[38] C.G. Fountzolas, G.A. Gazonas, B.A. Cheeseman, Computational modeling of tungsten carbide sphere impact and penetration into high-strength-low-alloy (HSLA)-100 steel targets, J. Mech. Mater. Struct. 2 (2007) 1965-1979.

[39] P.J. Hazell, G.J. Appleby-Thomas, K. Herlaar, J. Painter, Inelastic deformation and failure of tungsten carbide under ballistic-loading conditions, Mater. Sci. Eng. A. 527 (2010) 76387645. doi:10.1016/j.msea.2010.08.024. 
[40] N.J. Woolmore, The Failure of a Tungsten Carbide - Cobalt Cored Projectile Penetrating a Hard Target, Cranfield University, 2005. http://dspace.lib.cranfield.ac.uk/handle/1826/4657.

[41] T.J. Holmquist, G.R. Johnson, W.A. Gooch, Modeling the $14.5 \mathrm{~mm}$ BS41 projectile for ballistic impact computations, WIT Trans. State-of-the-Art Sci. Eng. 40 (2014) 73-86. doi:10.2495/978-1-84564-879-4/08.

[42] G.R. Johnson, W.H. Cook, Fracture characteristics of three metals subjected to various strains, strain rates, temperatures and pressures, Eng. Fract. Mech. 21 (1985) 31-48. doi:10.1016/0013-7944(85)90052-9.

[43] N. Bouaouadja, G. Orange, G. Fantozzi, F. Thevenot, P. Goeuriot, High Temperature Mechanical Behaviour of Cemented Carbides WC - (6.5, 12, 15 and 25) \% Co, Le J. Phys. Colloq. 47 (1986) C1-739-C1-743. doi:10.1051/jphyscol:19861112.

[44] S. Gu, S. Kamnis, Bonding Mechanism from the Impact of Thermally Sprayed Solid Particles, Metall. Mater. Trans. A. 40 (2009) 2664-2674. doi:10.1007/s11661-009-9959-1.

[45] S. Thiele, K. Sempf, K. Jaenicke-Roessler, L.-M. Berger, J. Spatzier, Thermophysical and Microstructural Studies on Thermally Sprayed Tungsten Carbide-Cobalt Coatings, J. Therm. Spray Technol. 20 (2011) 358-365. doi:10.1007/s11666-010-9558-0.

[46] Z. Arabgol, M. Villa Vidaller, H. Assadi, F. Gärtner, T. Klassen, Influence of thermal properties and temperature of substrate on the quality of cold-sprayed deposits, Acta Mater. 127 (2017) 287-301. doi:10.1016/j.actamat.2017.01.040.

[47] J.M. Guilemany, S. Dosta, J.R. Miguel, The enhancement of the properties of WC-Co HVOF coatings through the use of nanostructured and microstructured feedstock powders, Surf. Coatings Technol. 201 (2006) 1180-1190. doi:10.1016/j.surfcoat.2006.01.041.

[48] S. Yin, E.J. Ekoi, T.L. Lupton, D.P. Dowling, R. Lupoi, Cold spraying of WC-Co-Ni coatings using porous WC-17Co powders: Formation mechanism, microstructure characterization and tribological performance, Mater. Des. 126 (2017) 305-313. doi:10.1016/J.MATDES.2017.04.040. 
[49] M. Villa Vidaller, A. List, F. Gaertner, T. Klassen, S. Dosta, J.M. Guilemany, Single Impact Bonding of Cold Sprayed Ti-6Al-4V Powders on Different Substrates, J. Therm. Spray Technol. 24 (2015) 644-658. doi:10.1007/s11666-014-0200-4.

[50] A. List, F. Gärtner, T. Mori, M. Schulze, H. Assadi, S. Kuroda, T. Klassen, Cold Spraying of Amorphous Cu50Zr50 Alloys, J. Therm. Spray Technol. 24 (2014) 108-118. doi:10.1007/s11666-014-0187-x.

[51] J. Wu, H. Fang, S. Yoon, H. Kim, C. Lee, The rebound phenomenon in kinetic spraying deposition, Scr. Mater. 54 (2006) 665-669. doi:10.1016/j.scriptamat.2005.10.028.

[52] J. Henao, A. Concustell, S. Dosta, G. Bolelli, I.G. Cano, L. Lusvarghi, J.M. Guilemany, Deposition mechanisms of metallic glass particles by Cold Gas Spraying, Acta Mater. 125 (2017) 327-339. doi:10.1016/j.actamat.2016.12.007. 


\section{Figure 1}

Click here to download Figure: 1_Microstructure_model-approach_REVISED.eps

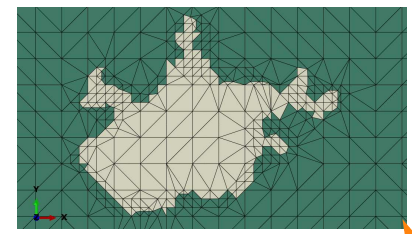

\section{FE mesh \\ FEmesh}

SEM micrograph

$-10 \mu \mathrm{m}$
Processed image

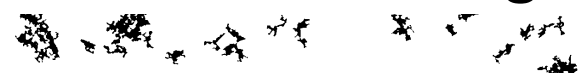
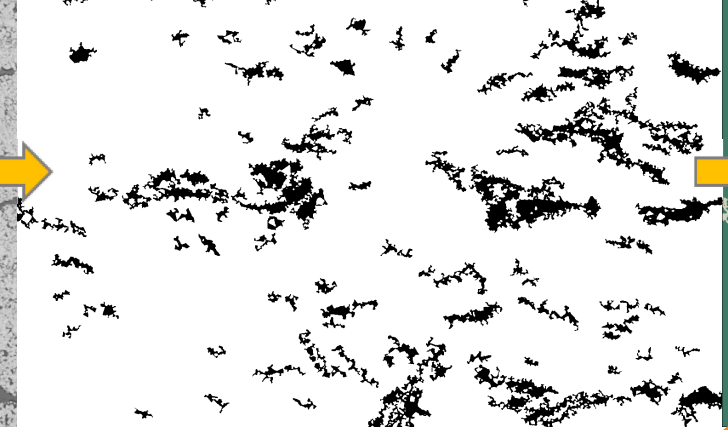
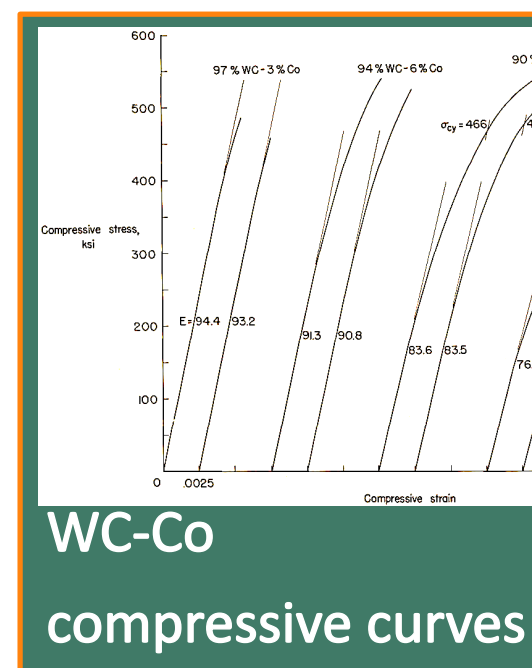

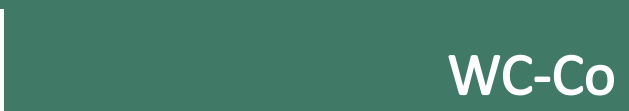

\section{tensile curves}

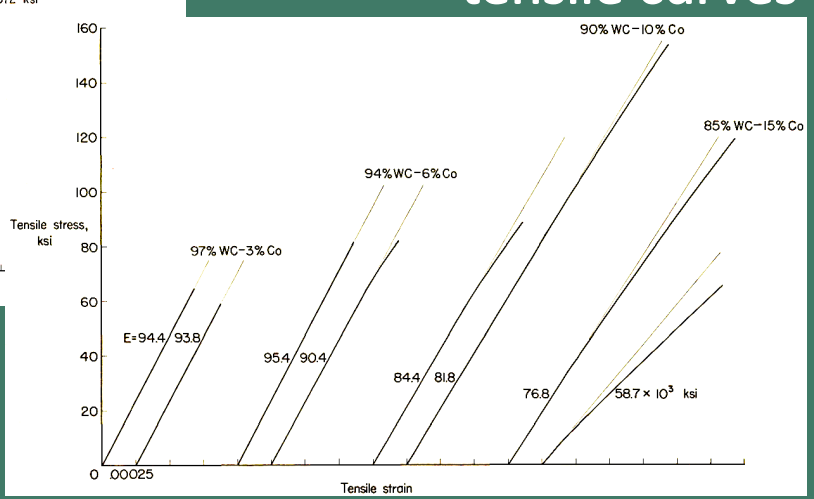

A.E. Johnson jr., NACA Technical Note 3309, December 1954
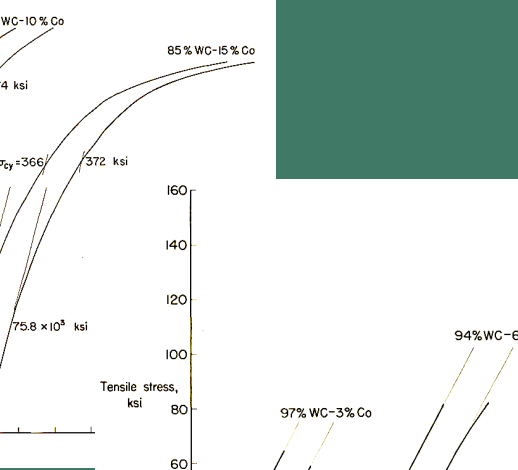

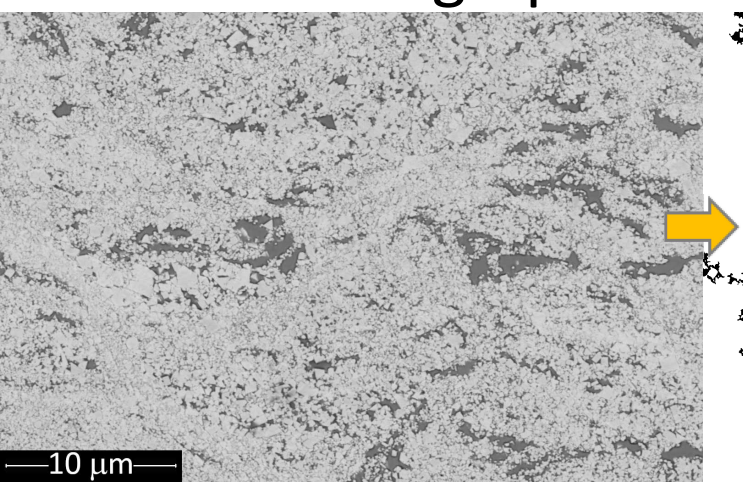


Click here to download high resolution image
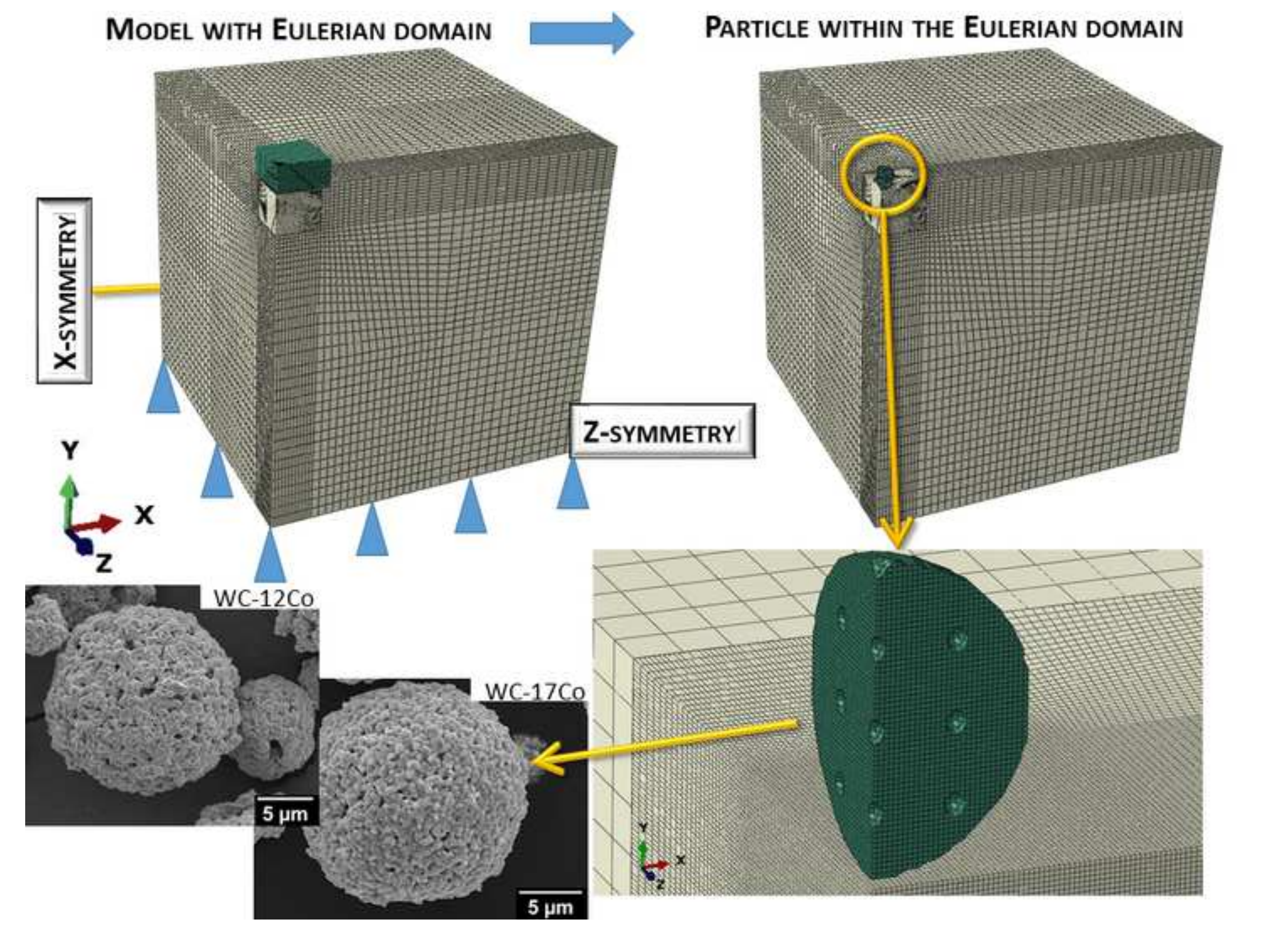


\section{STRESS - PLASTIC STRAIN CURVE WITH POWER-LAW FIT}

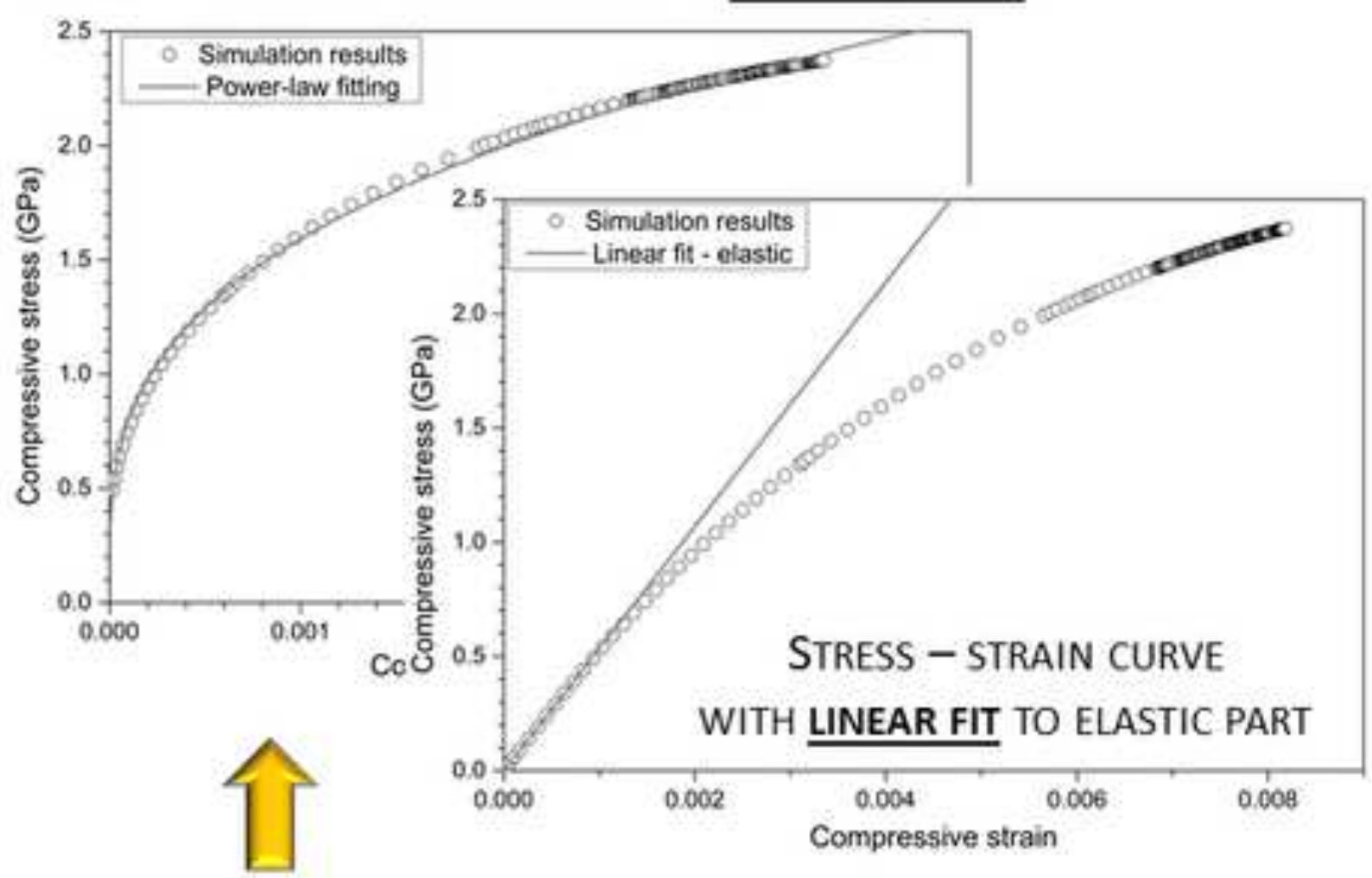

F.E. MESH

WITH BOUNDARY CONDITIONS
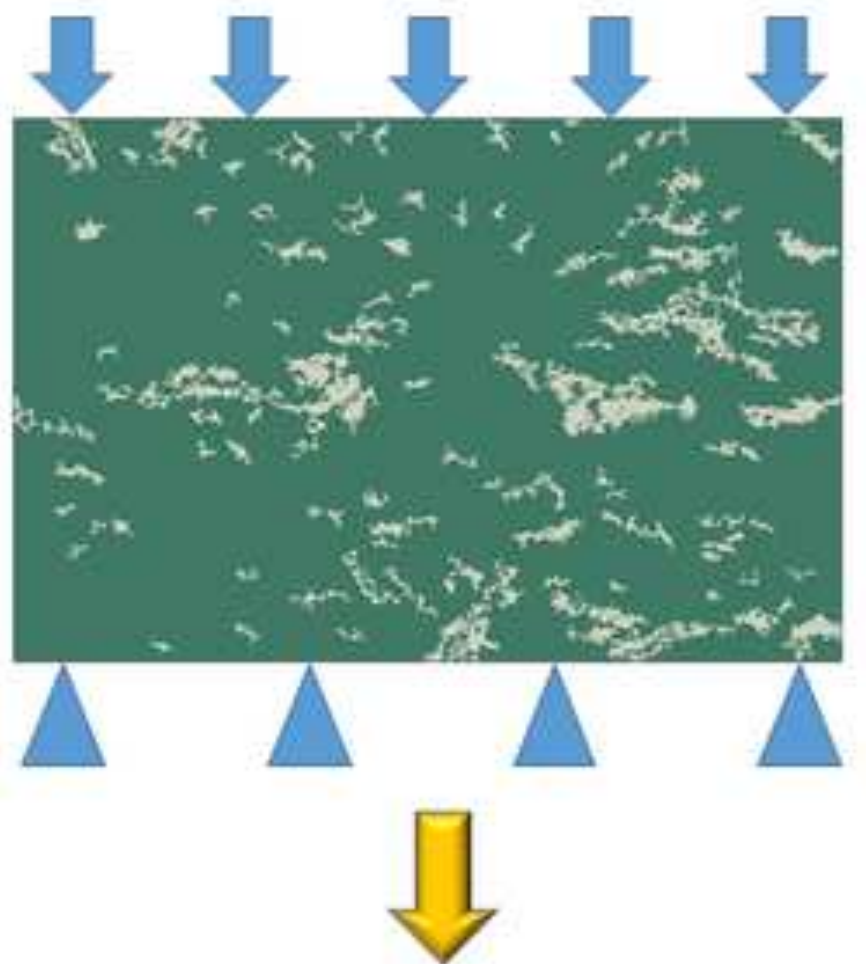

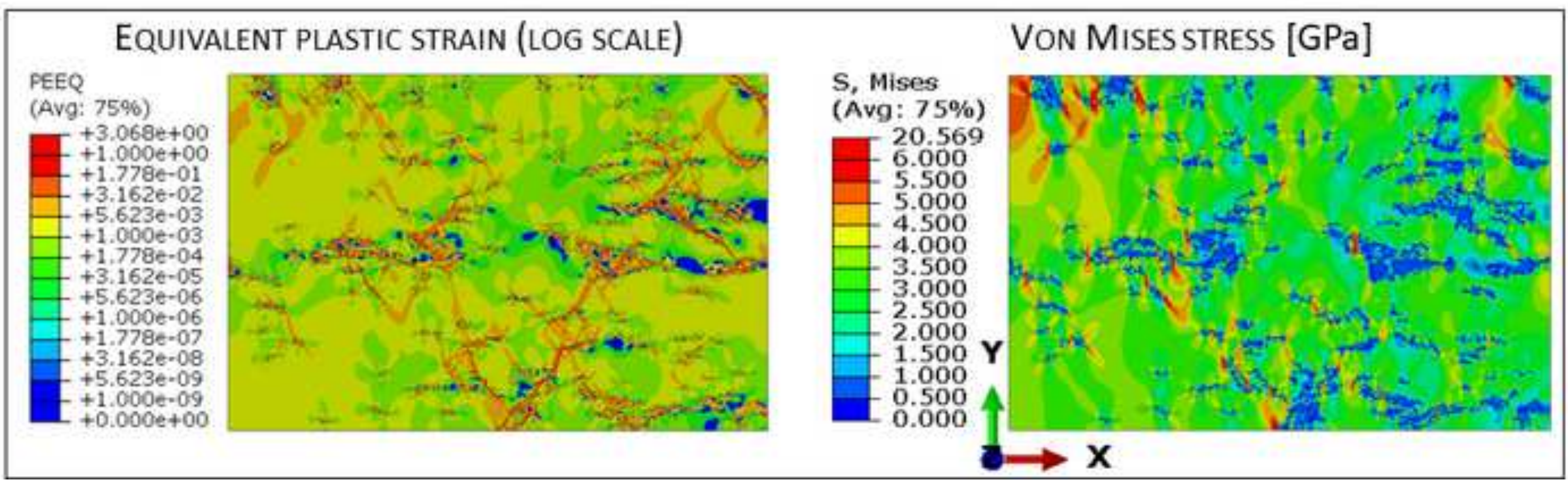




\section{Figure 4}

Click here to download high resolution image

TEMPERATURE [K] (PARTICLE + SUBSTRATE)
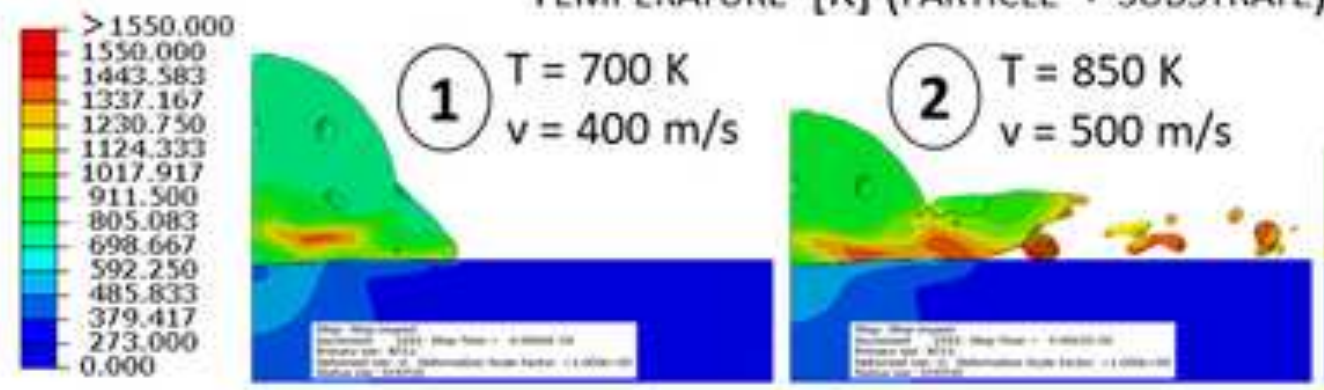

(3) $\begin{aligned} T & =1000 \mathrm{~K} \\ \mathrm{v} & =600 \mathrm{~m} / \mathrm{s}\end{aligned}$

ACCUMULATED FAILURE (PARTICLE)
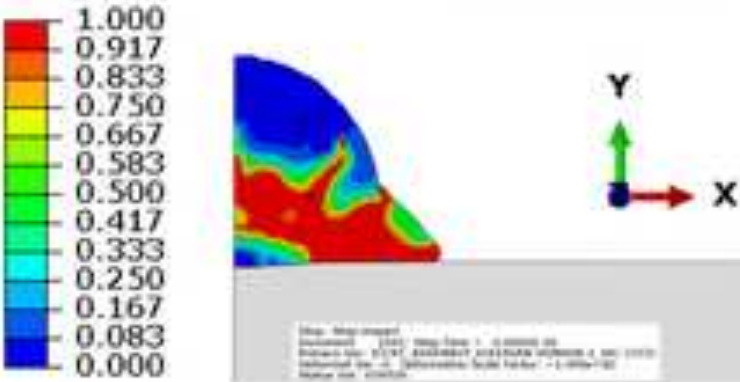

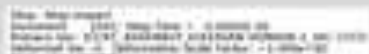
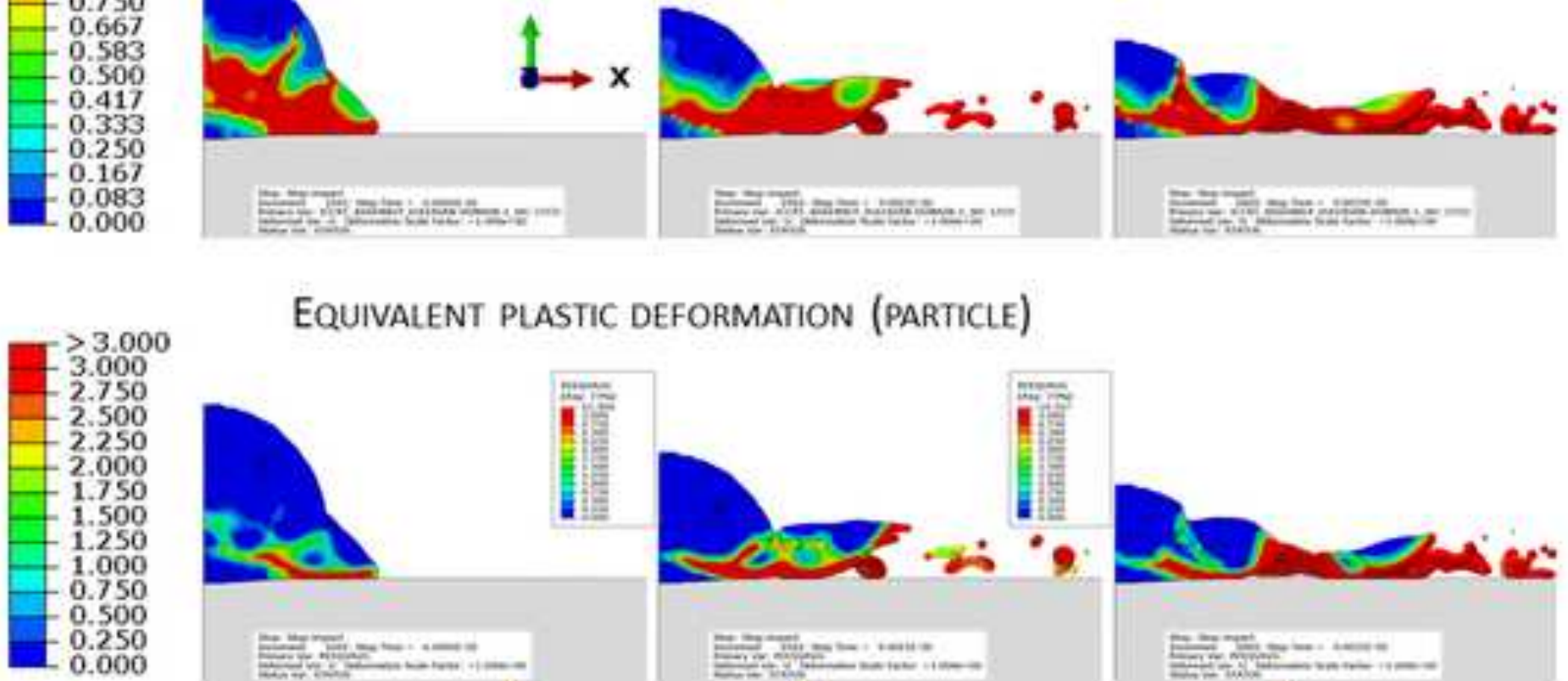

EquiVALENT PLASTIC DEFormation (PARTICLE)
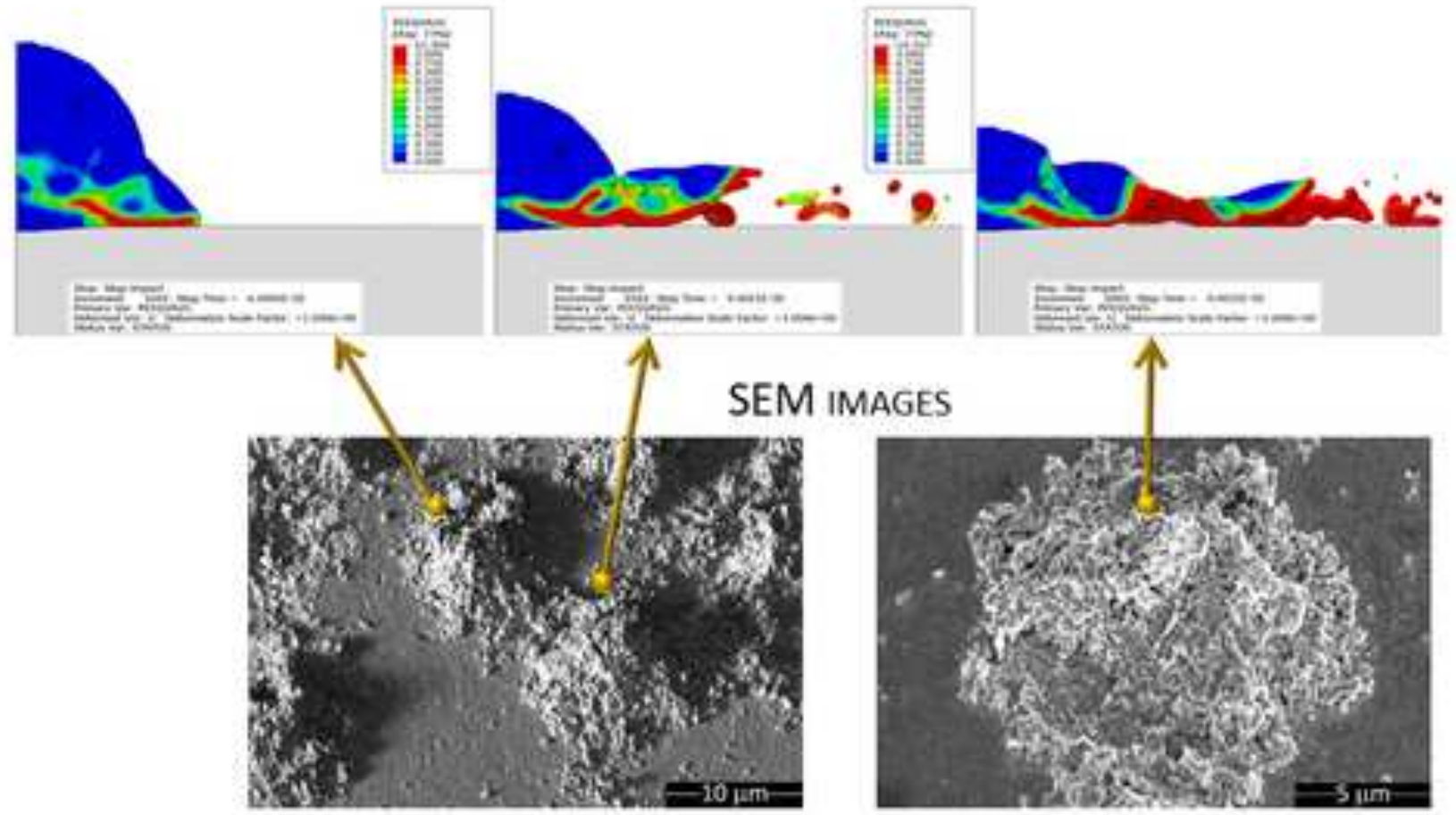
TEMPERATURE [K] (PARTICLE + SUBSTRATE)

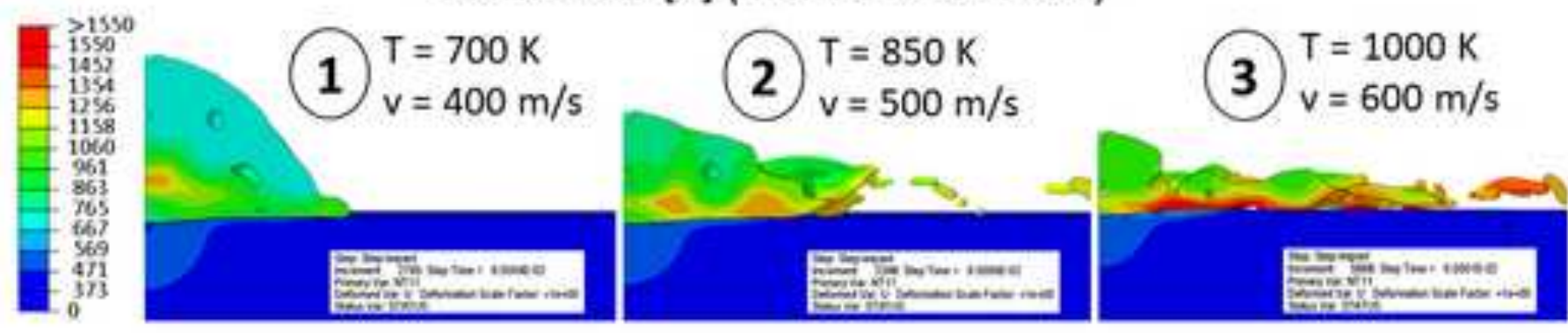

ACCUMULATED FAILURE (PARTICLE)
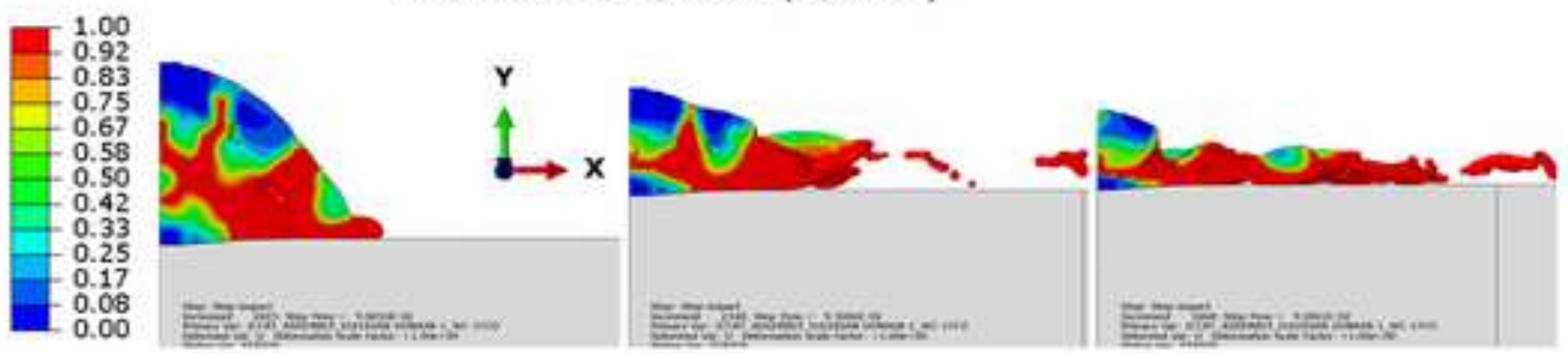

EquiVALENT PLASTIC DEFORMATION (PARTICLE)
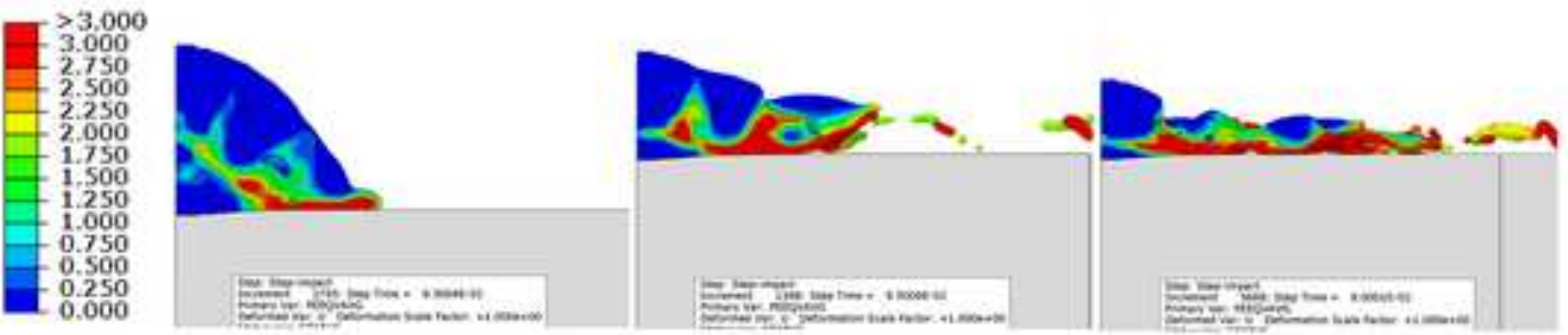

SEM IMAGES
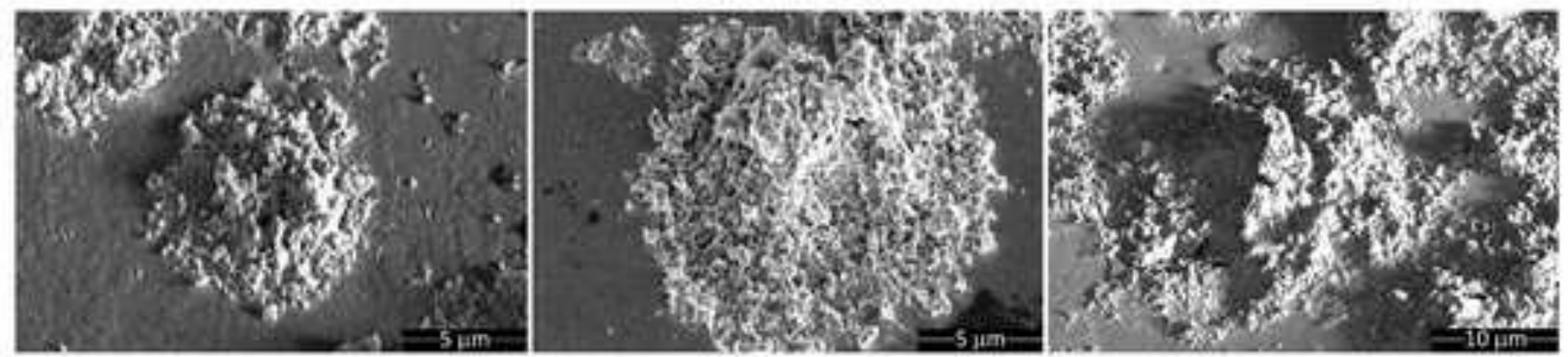


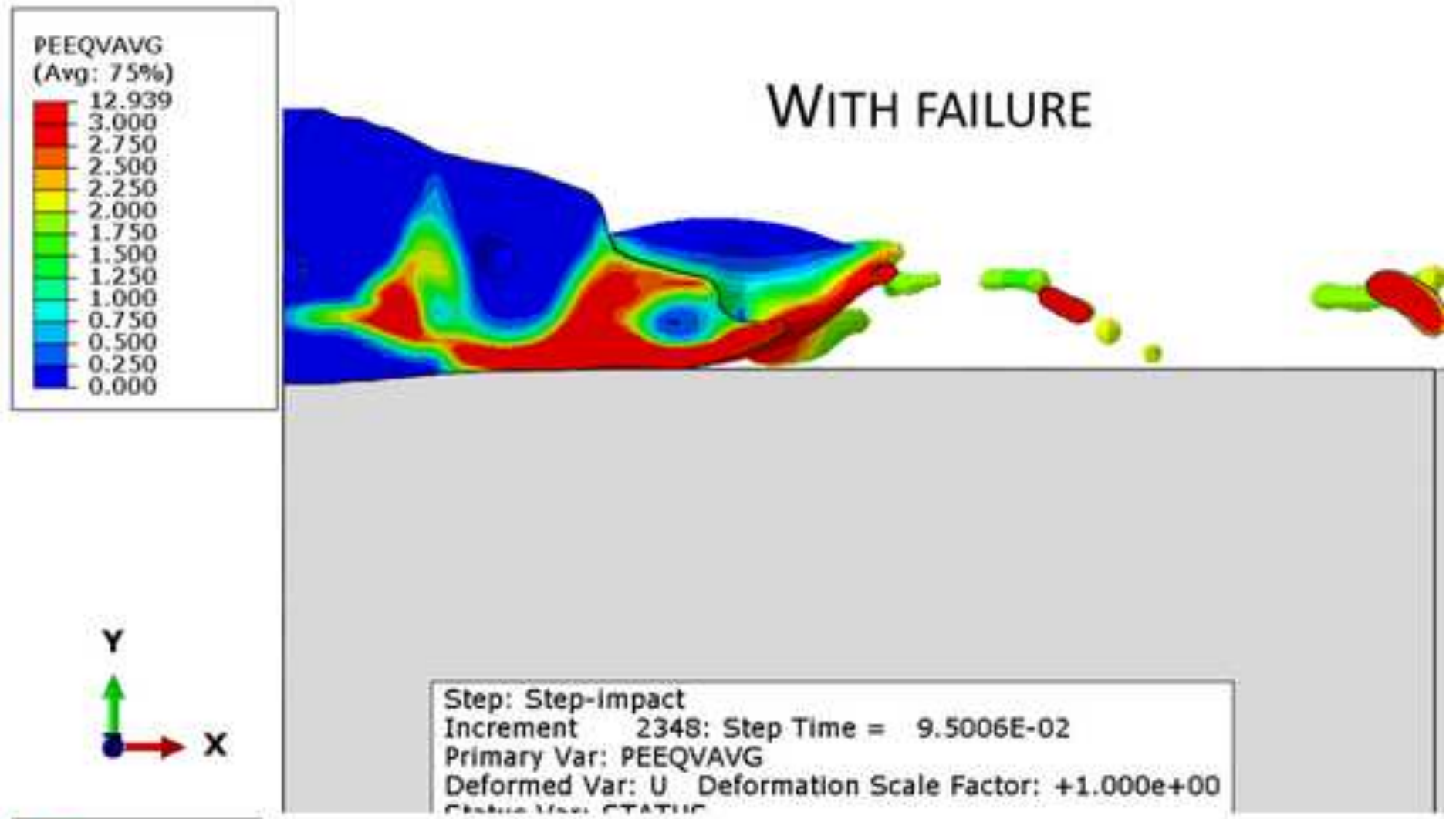

3.00

2.75

2.50

2.25

2.00

1.75

1.50

1.25

1.00

0.75

0.50

0.25

0.00

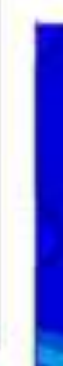

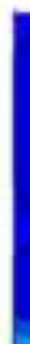

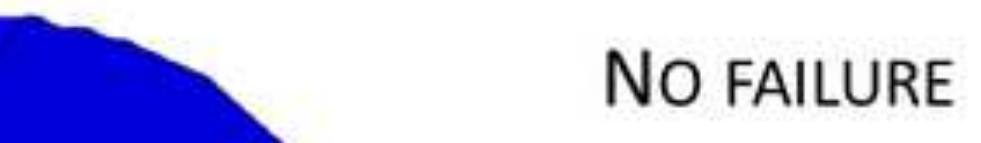

Step: Step-impact

Increment 633: Step Time $=3.0024 \mathrm{E}-02$

Primary Var: PEEQVAVG

Deformed Var: $U$ Deformation Scale Factor: $+1,00$ e +00 
Click here to download high resolution image

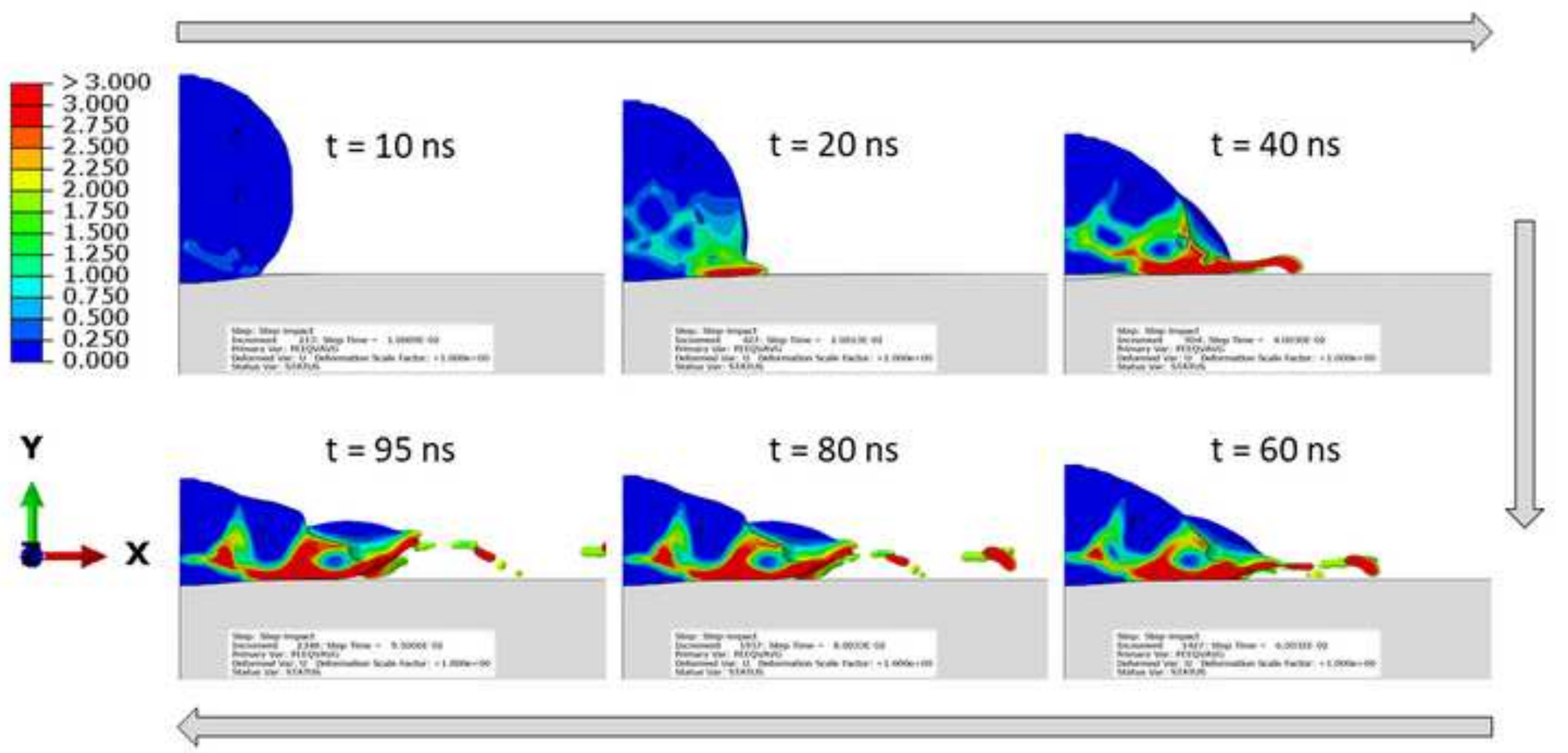


Click here to download high resolution image
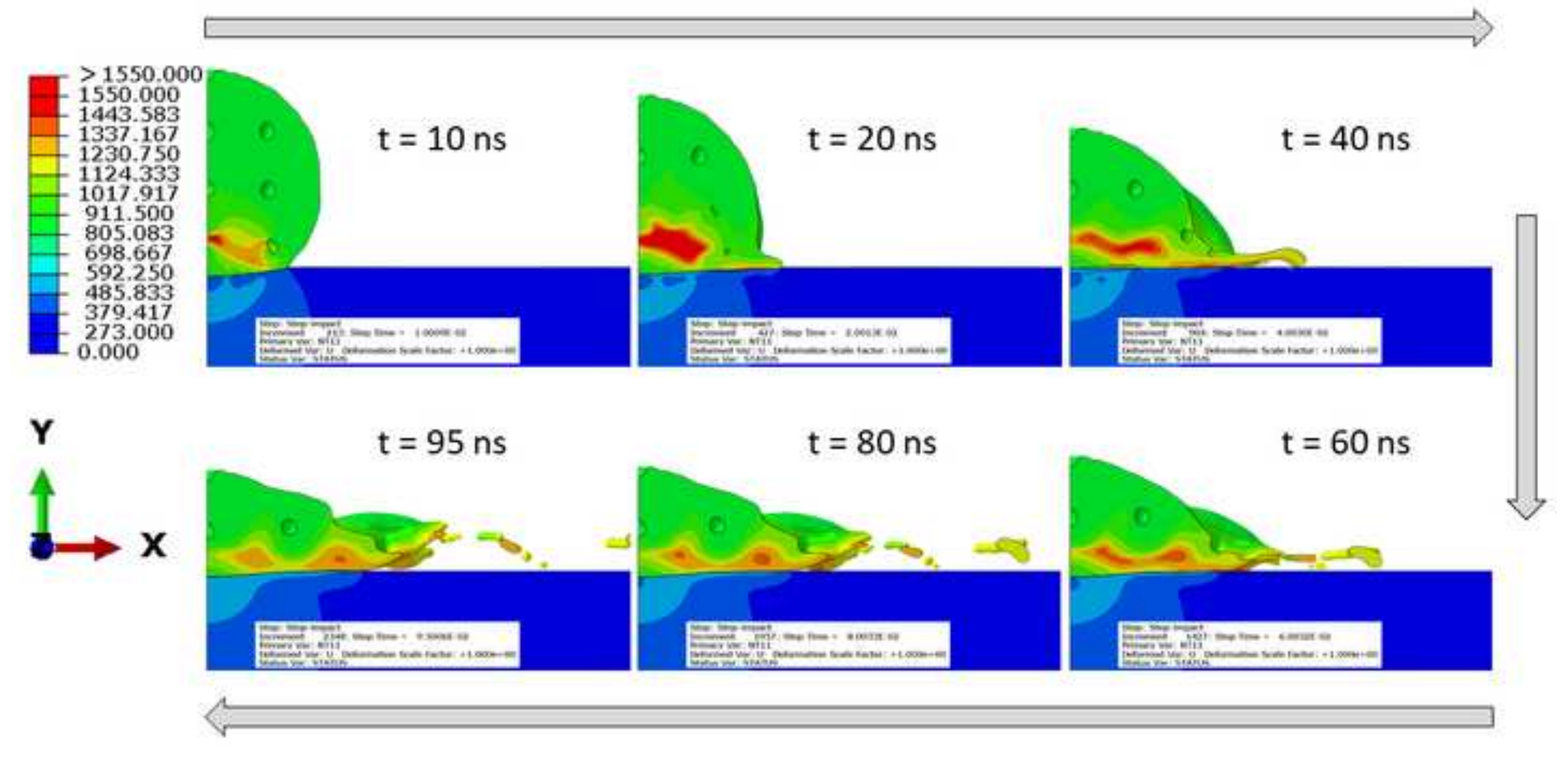

Click here to download high resolution image
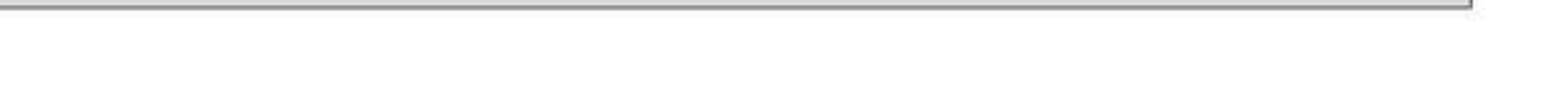
Click here to download high resolution image

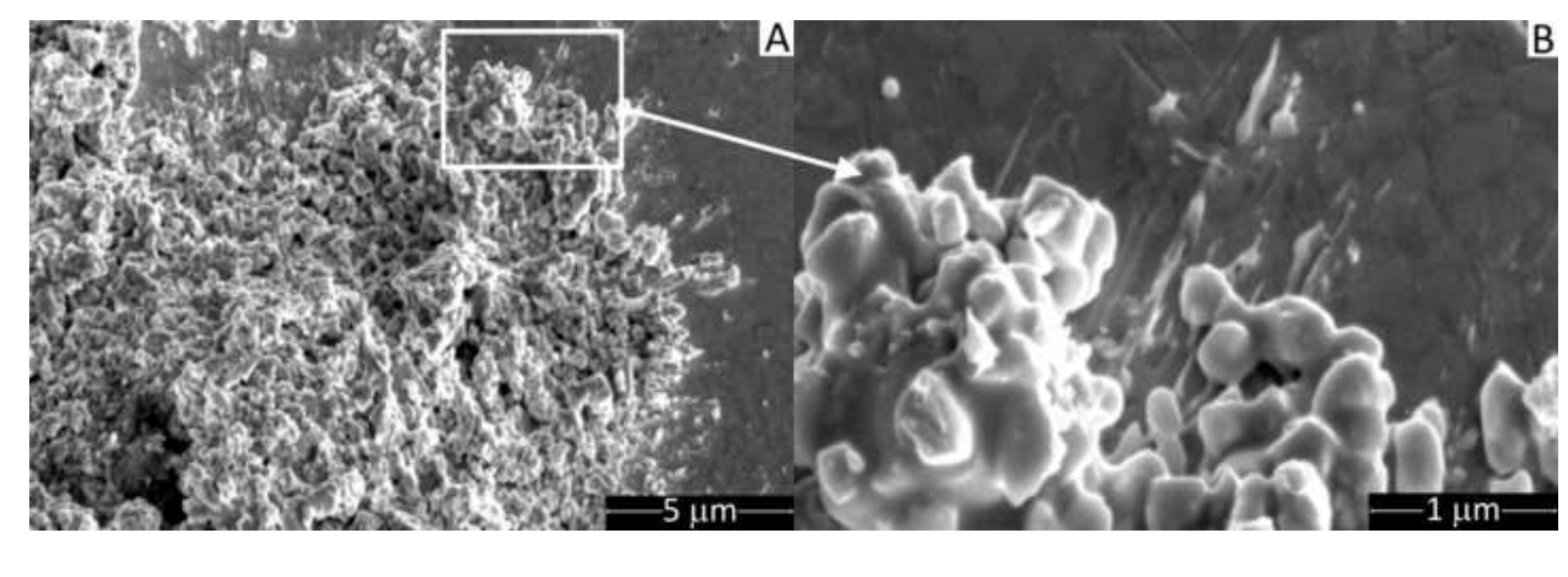

Why

B
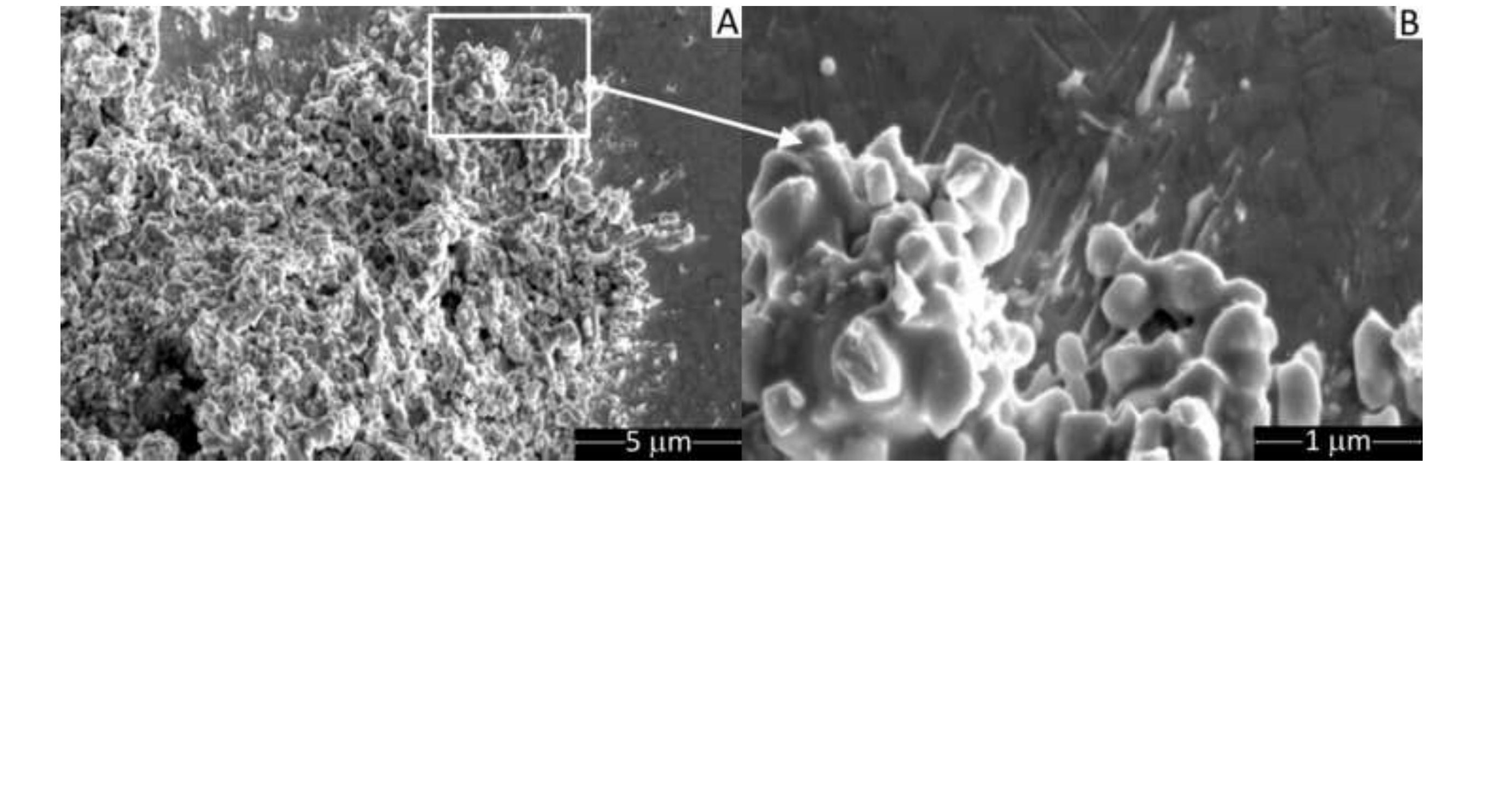

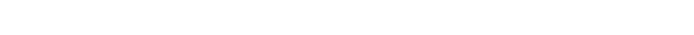

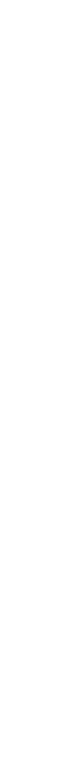




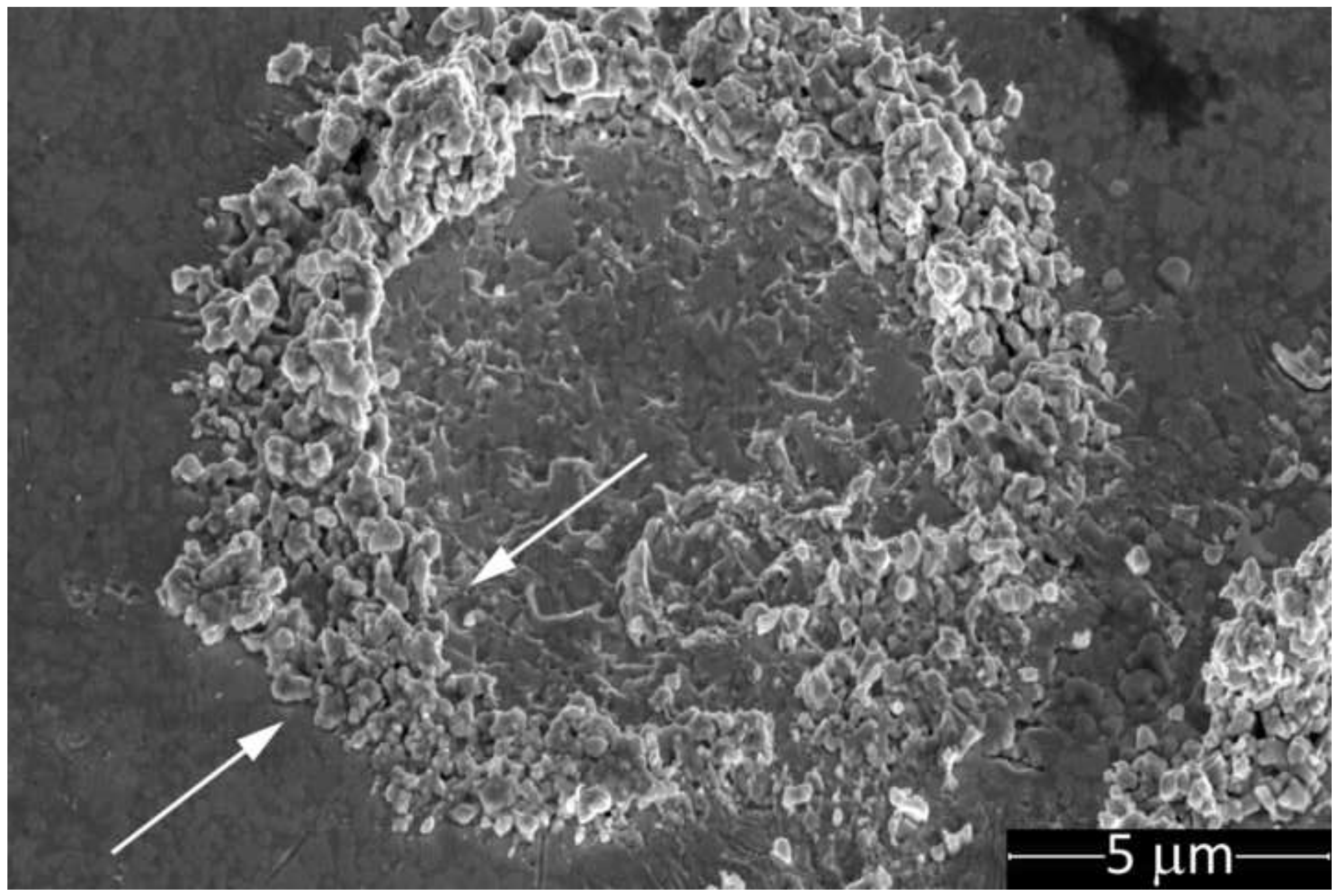


Click here to download high resolution image

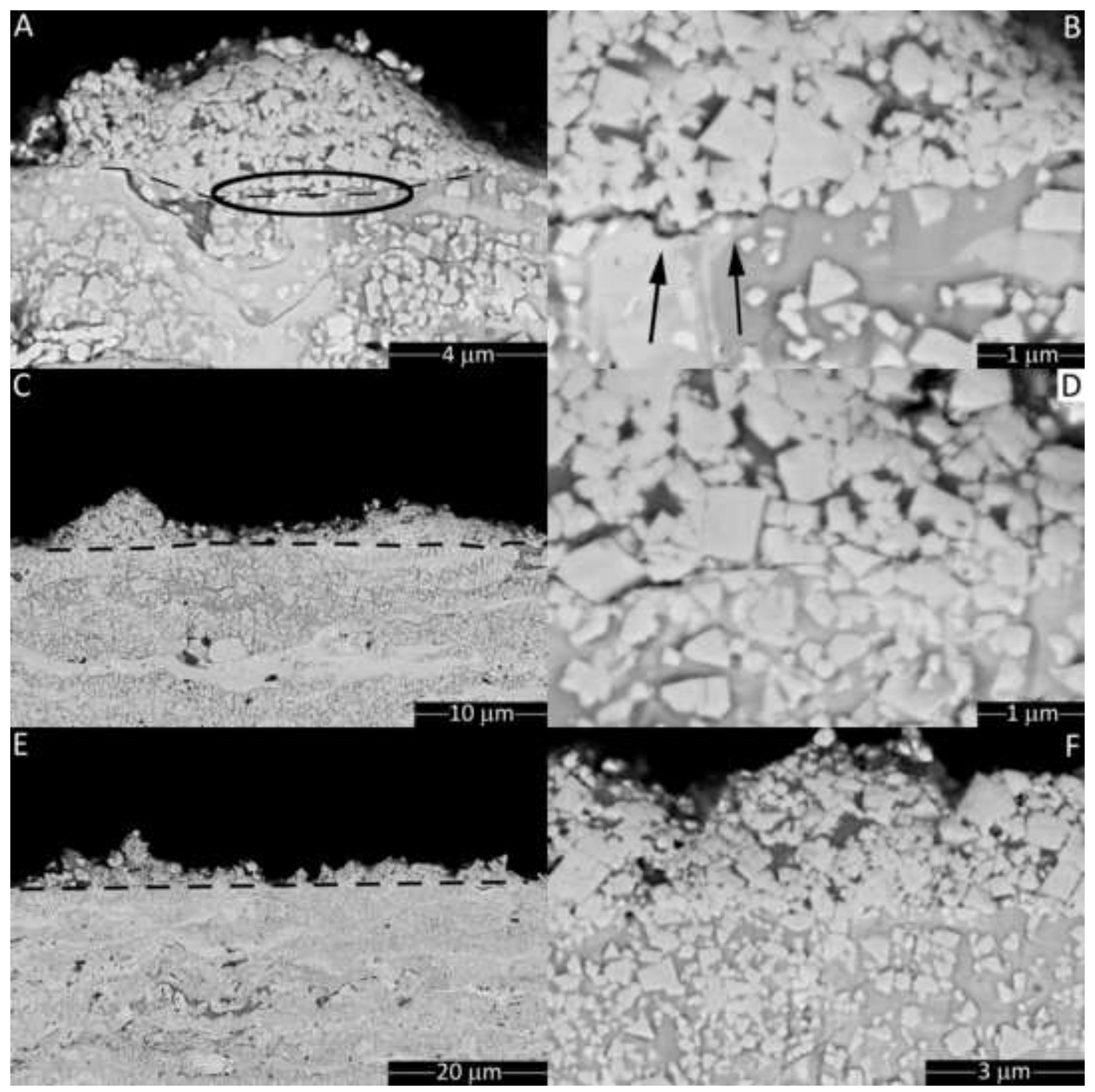


Figure 12
Click here to download high resolution image
neovave

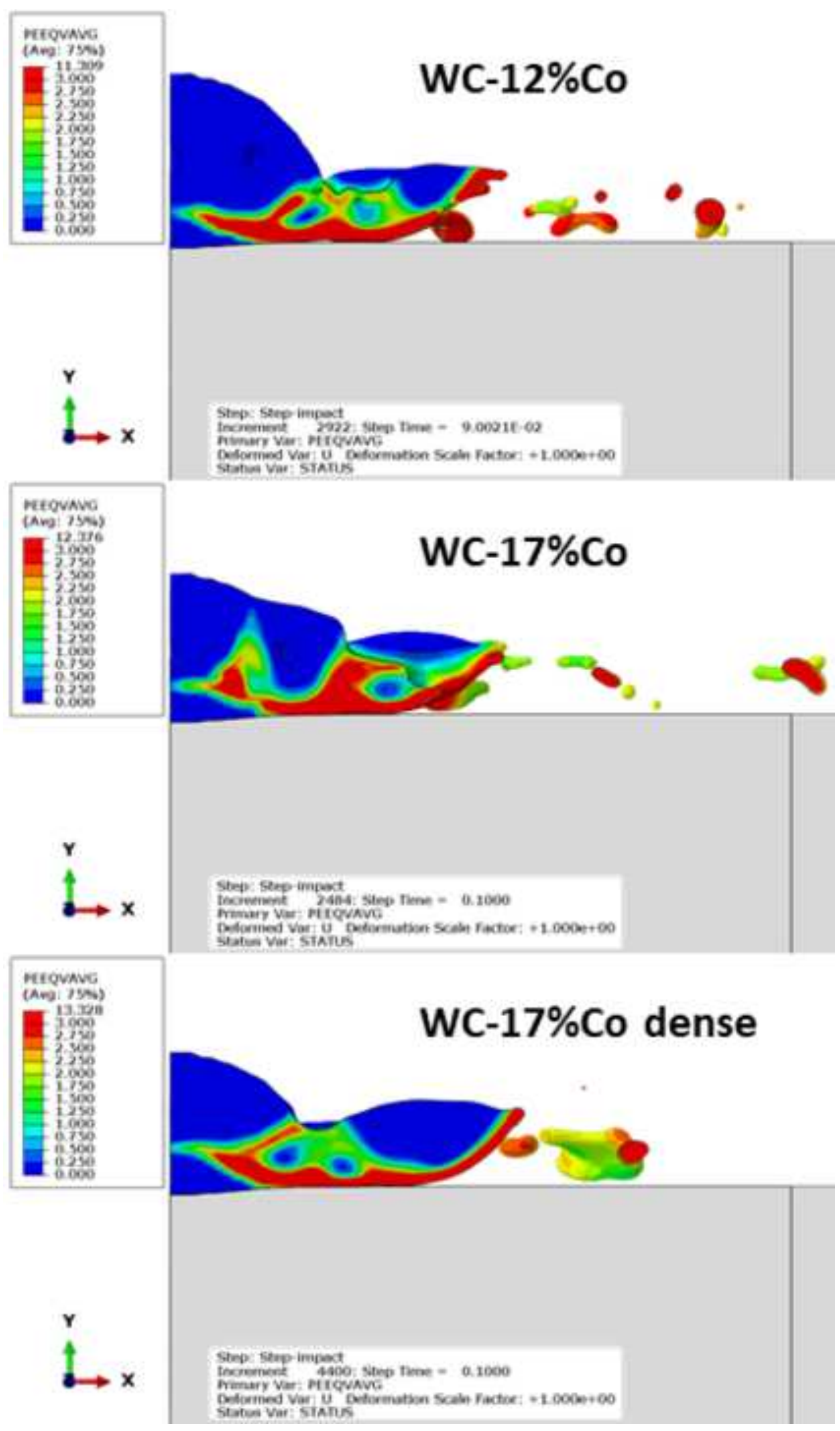

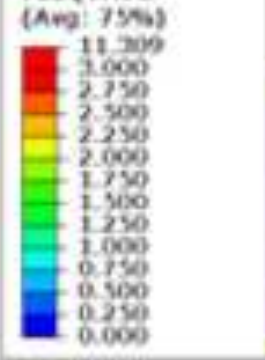

Stav-setpitipact

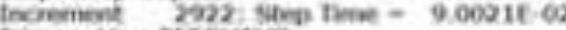

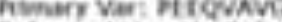

Deformed Var U Oeformation Scaln Fastor: + L.000eroci

Stahos Var: STanis

\section{WC-17\%Co}

thowenent zind: stes fiene $=0.1000$

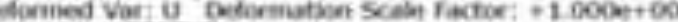

dates Var: STANUS 

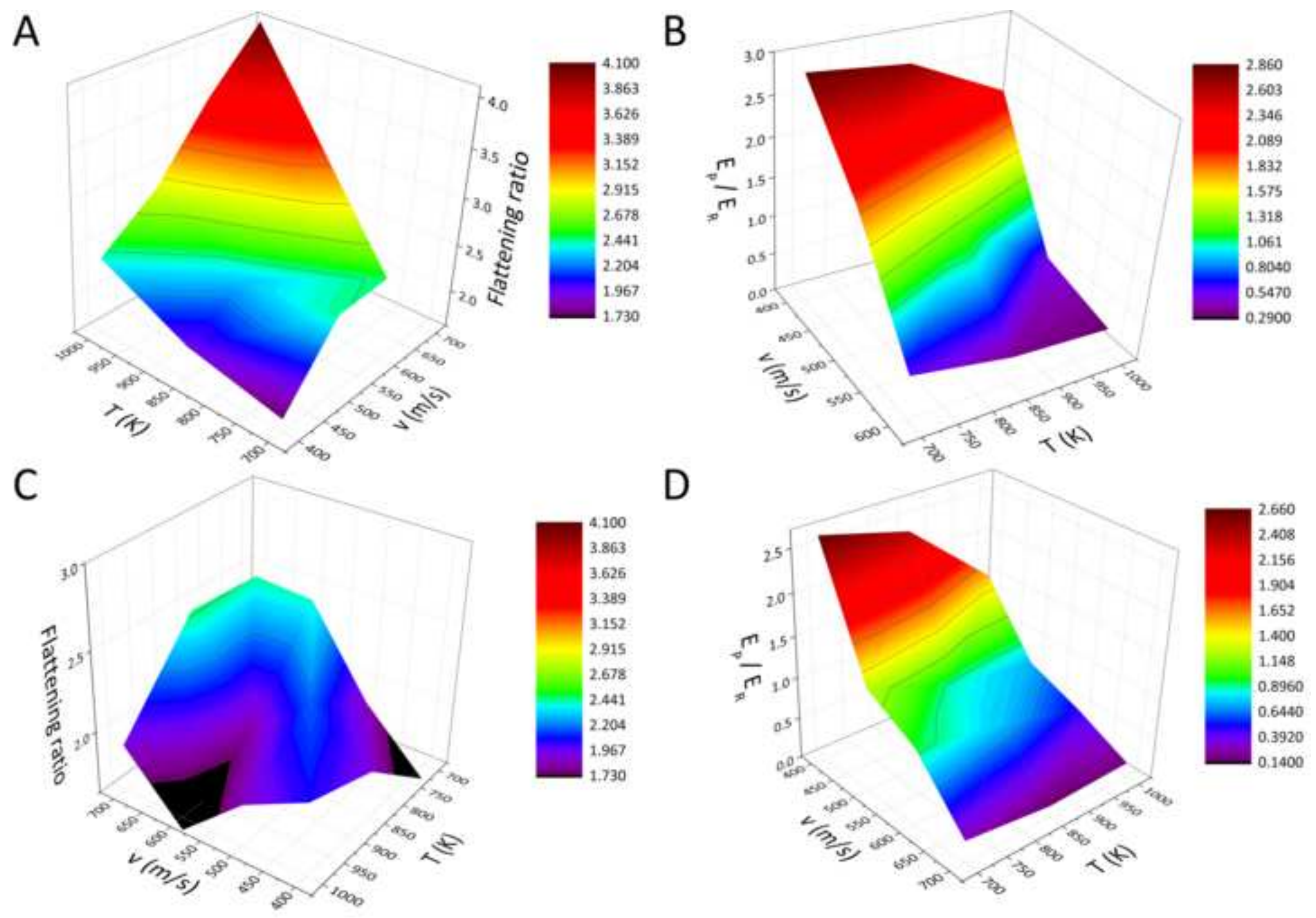


\section{Suggested reviewers}

Prof. Marcin Winnicki, Wroclaw University of Science and Technology, Poland marcin.winnicki@pwr.edu.pl

Dr. Maria Villa Vidaller, Helmut-Schmidt-Universität, Hamburg, Germany maria.villa@hsu-hh.de

Dr. Heli Koivuluoto, Tampere University, Finland

heli.koivuluoto@tuni.fi

Dr. Mario Tului, RINA - Centro Sviluppo Materiali, Roma, Italy mario.tului@ rina.org 


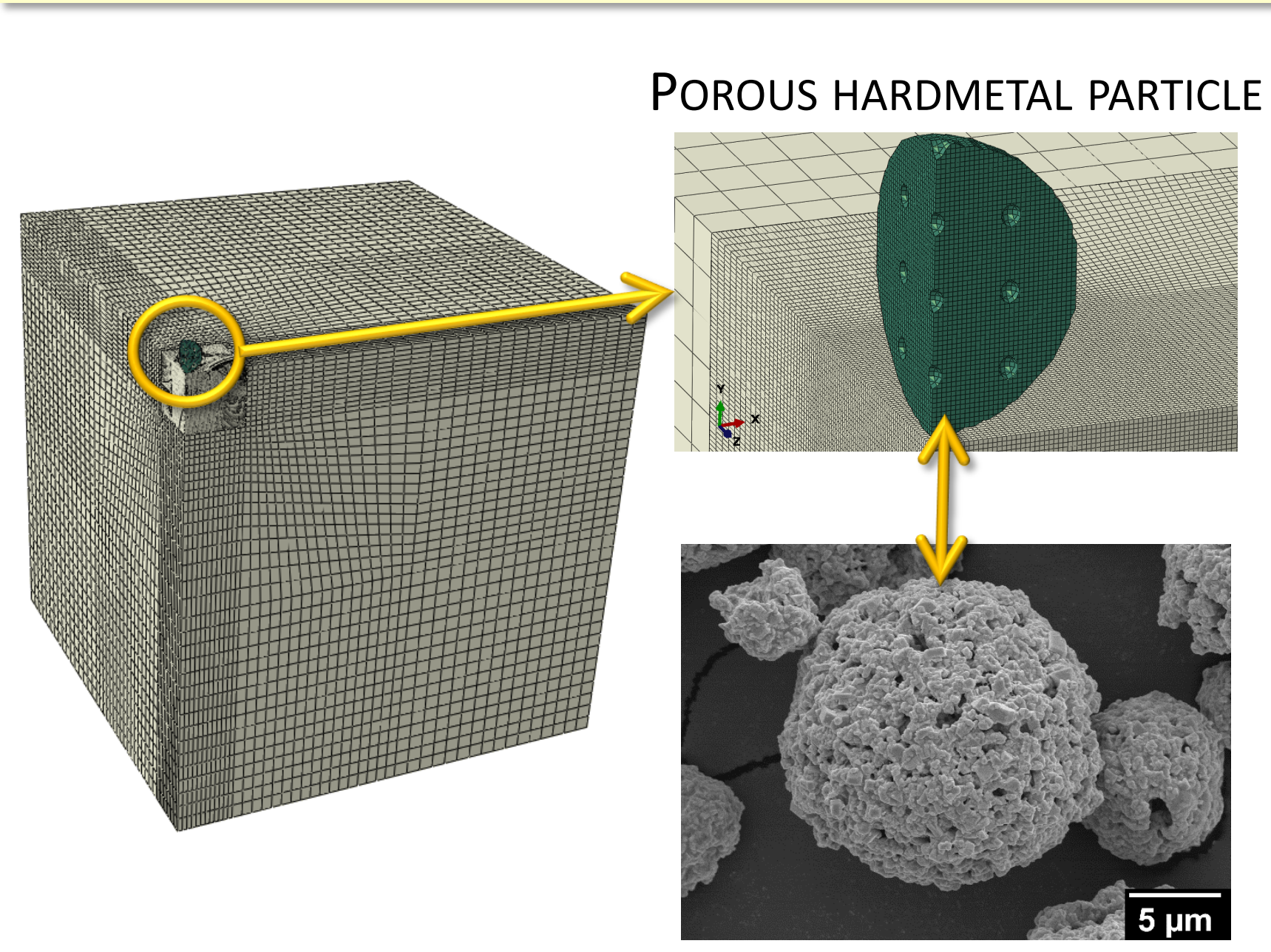
TEMPERATURE [K]

ACCUMULATED FAILURE
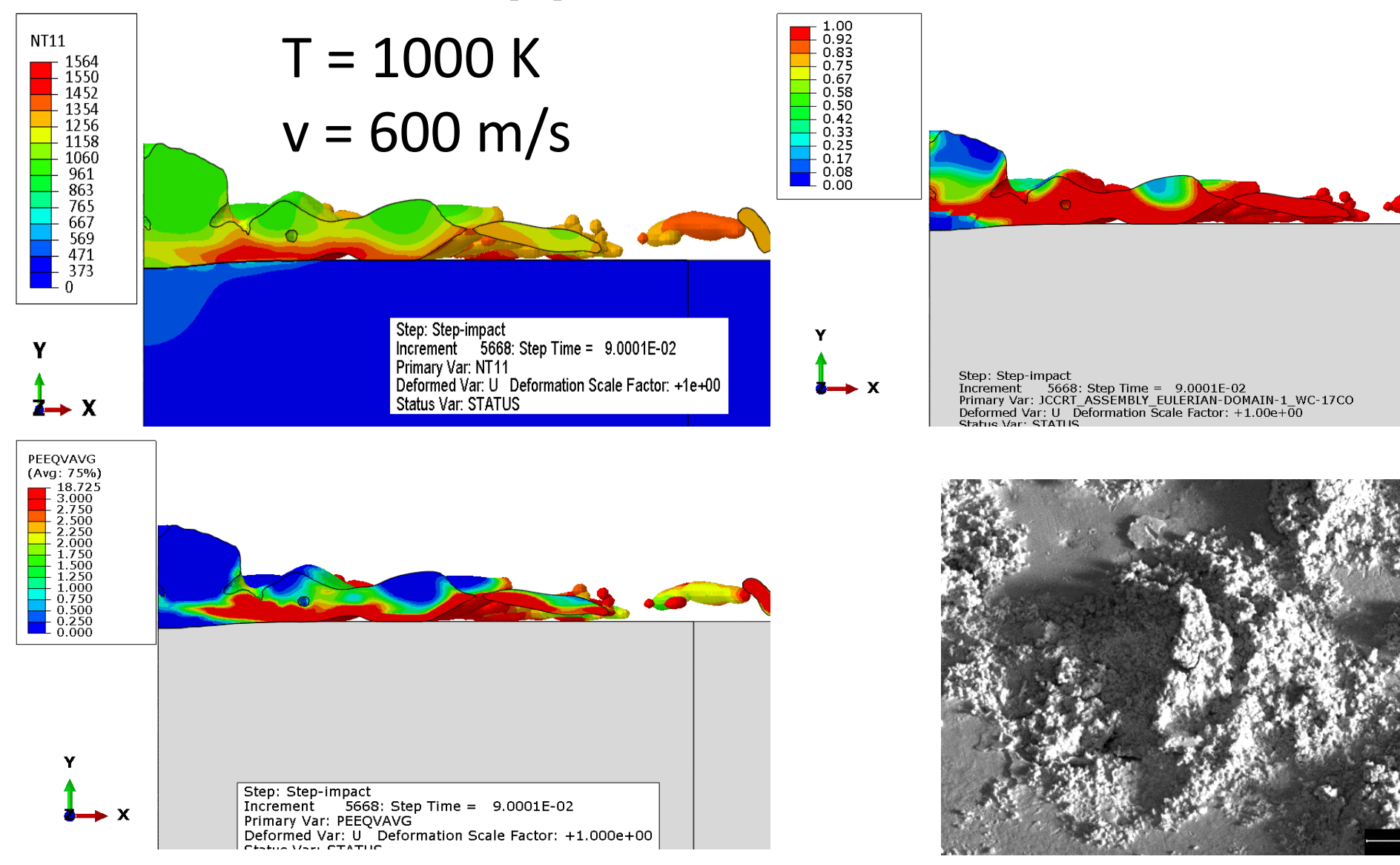

EQUIVALENT PLASTIC DEFORMATION

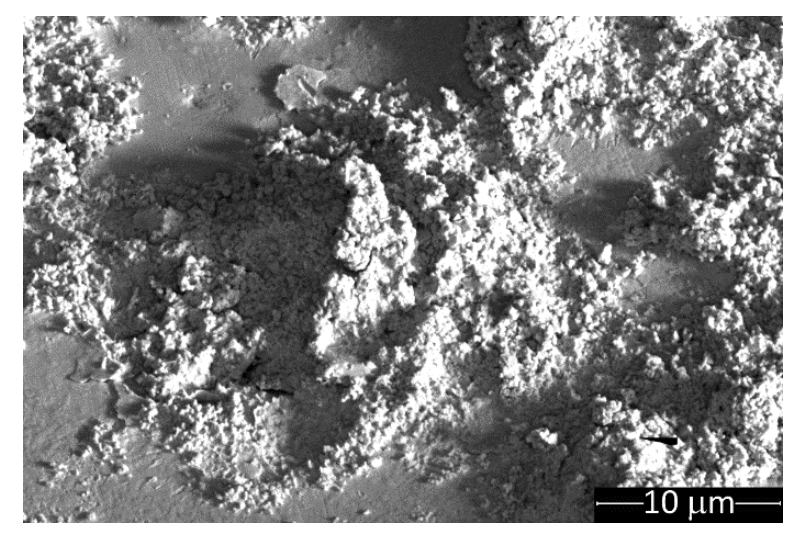

SEM MICROGRAPH 